\title{
Evaluation of Geomembranes Using an Ultrasonic Method
}

\author{
Nazli Yesiller1 and Sevil Sungur2
}

1. Associate professor, Department of Civil and Environmental Engineering, Wayne State University, Detroit, MI 48202

2. Construction coordinator, DPS Program Manager Team, LLC, Detroit, MI 48208

\begin{abstract}
An ultrasonic testing procedure was developed to evaluate geomembranes. The pulse-echo inspection technique was used on the surface of geomembranes without disturbing the material. The equipment required consists of a P-wave transducer, a pulser-receiver, and a signal acquisition system. Travel time of ultrasonic waves and waveform energy are measured to evaluate the condition of geomembranes. Laboratory tests were conducted to assess the effectiveness of the method. Defects that simulate installation damage and various inservice degradation conditions were in-duced on samples. The defects were identified with the ultrasonic method at a success rate higher than $98 \%$. Changes in the thickness or the microstructure of the geomembranes were identified. Surficial and internal defects were located. Defects that were not visible from the measurement surfaces were identified. This method appears promising to monitor the condition of geomembranes in the laboratory or in the field and to assess in situ damage to geomembranes.
\end{abstract}

Geomembranes are used as barrier layers against liquid and gas transmission in various applications including liners for waste containment facilities, canals, and dams; waterproofing for highways, tunnels, buildings, and earth retaining structures; and liners for general prevention of seepage and moisture migration. Defects in geomembranes adversely affect the performance of the material. In the field, defects are commonly caused by installation damage, mechanical stresses, and chemical and environmental exposure.

Case histories of failures due to improperly installed geomembranes have been reported in the literature. Bonaparte and Gross (1990) presented data from 30 landfills and surface impoundments that were lined with double-liner systems. They concluded that there was leakage from the top geomembrane liners in all 30 of the landfills, due to defects in the geomembranes. The defects were as-sumed to have occurred during construction of the facilities. Laine and Mosley (1993) presented results of 169 electrical leak location surveys conducted on geomembranes installed in waste containment facilities. The number of leaks identified ranged from 0 to 144 per 10,000 m2 of liner with an average of 14 leaks. Darilek et al. (1995) conducted similar leak location surveys and reported the presence of similar amounts of defects (about 22 defects per 10,000 $\mathrm{m} 2$ of geomembrane) in a liner used for a hazardous waste facility. The size of the defects varied from a few millimeters to tens of millimeters. They stated that the largest defects were in the parent ma-terial as opposed to the seams.

Comer et al. (1996) evaluated polyethylene canal liners subse-quent to 3 and 12 
years of exposure in the field. The tensile strength of the exposed liners was lower than their strength as-received. The decrease was attributed to the scratches that occurred during installation. Giroud et al. (1994) investigated the effects of scratches on tensile strength of HDPE geomembranes in the laboratory. They concluded that the yield strain could be up to $50 \%$ lower for scratched geomembranes compared to intact geomembranes when the scratches penetrated up to $50 \%$ of the thickness of the geomembranes. Tensile strain can also affect the perfor-mance of geomembranes. Park et al. (1995) investigated the transfer of aqueous solutions of organic compounds through tensioned and untensioned geomembranes. The mass flux of the solvents increased as the thickness of the geomembranes decreased under tension.

In addition, case histories were reported indicating deterioration and failure of geomembranes due to environmental and chemical exposure (Peggs 1988, Fisher 1989, Peggs and Carlson 1989, 1990). In most cases, brittle failure of geomembranes occurred at locations of cracks and imperfections on the geomembrane surfaces.

Damaged or degraded geomembranes in operational facilities cannot be identified using conventional destructive test methods without disturbing the material. For most methods, removal of samples is required to locate defects and to assess damage to geomembranes. Existing nondestructive field methods are designed to detect only defects such as holes and tears that penetrate the entire thickness of geomembranes (Darilek et al. 1989, Peggs 1993).

In this paper, an ultrasonic method to evaluate the condition of geomembranes is described. Laboratory tests were conducted to assess the effectiveness of the method. Defects representative of installation and in-service damage mechanisms were induced on geo-membrane samples and were identified using the ultrasonic method. The ultrasonic method is simple, fast, and sensitive, and it can be used both in the laboratory and in the field without disturbing the geomembrane under investigation.

\section{Background}

Ultrasonic testing is used for nondestructive evaluation of materials and structures. The method allows for the determination of material properties, detection of damage or discontinuities in materials, and assessment of the condition of materials and structures (Bray and McBride 1992). Ultrasonic testing is commonly used for quality control of materials production and also for monitoring the performance of a material or structure during its service life by conducting repeated measurements (Green 1987). Removal of samples is not required and, in most cases, access only to one surface is needed. Ultrasonic waves are mechanical waves with frequencies higher than $20 \mathrm{kHz}$ that propagate in mass media. Ultrasonic inspection consists of sending and receiving waves in materials. Condition and properties of the test materials are determined by analyzing various properties of the sent and received waves.

Ultrasonic testing has been used to a limited extent to evaluate geomembranes. Most of these applications are for evaluation of seams (Koerner 1998). The methods available are the pulse-echo method, the impedance plane method, and the ultrasonic shadow method. The seams can be evaluated quickly and it is possible to achieve $100 \%$ coverage with these methods. The pulse-echo method consists of sending a high-frequency ultrasonic wave from the top of a seam and analyzing the reflections from the bottom of the seam. Travel time of the waves through the seam is correlated to the condition of the 
seam. The impedance plane method consists of sending a continuous wave through a seam. The direction of the acoustic impedance vector changes depending on the quality of the seam. In the ultrasonic shadow method, a transmitting transducer is placed on the upper geomembrane on one side of the seam and a receiving transducer is placed on the lower geomembrane across from the seam. The amplitude of the signal transmitted between the transducers is an indication of the condition of the seam.

An application of ultrasonic testing to evaluate parent material (as opposed to seams) was reported by Steffen and Asmus (1993). Problems were encountered during the installation of a polyethylene geomembrane in a waste disposal facility in Germany. The geomembrane was over-stretched at locations near the anchor trenches. Also, the geomembrane had expanded and contracted due to temperature variations. Ultrasonic measurements were conducted to determine the thickness of the geomembrane. Local reductions in the thickness were detected using the ultrasonic tests. While details were not provided in the paper, it is believed that the pulse-echo inspection technique was used on the exposed surface of the geomembranes. Velocity of wave transmission in the geomembrane was known, and this was used together with wave travel times obtained during testing to determine thickness. It was recommended that both destructive and nondestructive tests be conducted during geomembrane installation to detect defects in a timely manner and to conduct immediate repair (Steffen and Asmus 1993).

In summary, it has been shown that ultrasonic testing can be used to evaluate geomembranes. This study provides an extensive investigation of the use of ultrasonic testing to identify defects that may occur in geomembranes due to various potential damage mechanisms.

\section{Equipment}

The electronic equipment used in this study consists of three units (Fig. 1): a transducer, a thickness measurement gage, and a digital oscilloscope. The procedures for setup and use of the elec-tronic equipment are described in detail by Sungur (1999).

1. A P-wave transducer with 10-MHz-center-frequency and a delay line is used for the tests. Delay line transducers that are commonly used for testing thin materials provide good near surface resolution for accurate determination of arrival times (McIntire 1991).

2. A commercially available thickness gage is used for data ac-quisition and analysis. The thickness gage contains both a pulser that actuates the transducer and a receiver that receives the waveforms generated in a geomembrane sample. The pulser generates a broadband spike voltage that can be ad-justed to 30 volts, 60 volts, or 110 volts. The receiver band-width ranges from $2 \mathrm{MHz}$ to $30 \mathrm{MHz}$.

3. A digital oscilloscope is used for monitoring setup parame-ters and viewing the waveforms, as well as recording the waveforms for further analysis. The oscilloscope consists of an adapter box and a computer.

\section{Test Procedure}

The ultrasonic pulse-echo inspection technique with a single transducer was used to evaluate geomembranes (Fig. 2). Tests were conducted by placing the ultrasonic transducer on the sur-face of a geomembrane sample. Water was used as the 
coupling medium. A surcharge weight was mounted on the transducer to ensure that the transducer was stable on a sample. Transmission and reflection phenomena that result from a single excitation of the transducer are presented in Fig. 2. Initially, the incident pulse travels through the delay line and strikes the top surface of a geo-membrane sample. The reflection from this interface, $R 1$, travels back to the transducer. The transmitted wave, $T$, then travels through the geomembrane sample. Another reflection, $R 2$, is generated when the transmitted wave strikes the bottom surface of the geomembrane. This reflection also travels back to the transducer.

The waveforms generated in the tests are represented as arrays of 800 data points plotted on the abscissa with amplitude on the ordi-nate. The time associated with a waveform can be determined, as the time interval between each data point is known. A typical wave-form obtained for a geomembrane sample is presented in Fig. $3 a$. The reflections from the top and the bottom surface of the sample are identified on Fig. $3 a$. The time difference between these reflec-tions is dependent on the thickness of a sample and velocity of wave propagation through a sample. Additional reflections, $R 3$ and $R 4$, between $R 1$ and $R 2$, are generated when there are surficial or internal defects present in a geomembrane. An example of a waveform obtained from a sample with scratches on the surface is presented in Fig. $3 b$.

In the ultrasonic tests, two parameters are determined: travel time and waveform energy.

1. Travel Time: The time interval between the top surface reflection and the bottom surface reflection is the travel time of waves through a sample, which is dependent on the thickness and velocity of a sample. The travel time is used to determine the thickness of a sample if the velocity is known, or conversely, the time is used to determine velocity if the thickness of a sample is known.

Travel time of ultrasonic waves is affected by the microstruc-tural properties of a geomembrane. Degradation mechanisms that affect the chemical composition or microstructure of geomembranes cause changes in the velocity, and thus the travel time, of P-waves in the geomembrane. Defects that change the effective thickness of geomembranes also cause changes in travel time. Defects on the surface of geomembranes and internal defects can also affect the travel time, due to changes in the travel path of the waves.

2. Waveform Energy: The energy $(E)$ is a measure of the amplitude of the waveform over a specified interval (Fig. 4). The energy is determined as the sum of the squares of the amplitudes (voltage) with respect to a designated reference value (baseline amplitude) multiplied by the interval between data points. The equation for energy $(E)$ is:

$$
E=\sum_{i=1}^{N}\left[\left(v_{i}-v_{\text {base }}\right){ }^{2} \Delta p\right]
$$

where $N$ is the number of points in the waveform over the energy measurement interval, viis the amplitude of point " $i$ " in volts, vbase is a designated baseline amplitude (volts), and $\Delta p$ is the difference between consecutive points in the waveform which is equal to 1 . The baseline amplitude is determined using the portion of a wave-form that precedes the top surface reflection (Fig. 4). 
The waveform for a sample with no surficial or internal defects is expected to be similar to the waveform presented in Fig. 3a. The energy for this waveform is low due to the relatively smooth signal that is close to the baseline between the top and the bottom surface reflections. Additional reflections generated due to defects on the surface of the geomembrane, defects that penetrate the entire thick-ness of the geomembrane, or internal defects that are not visible from the outside, increase the energy of the waveform. Energy for a waveform obtained on a sample with such defects (Fig. $3 b$ ) is expected to be higher than the energy obtained for a geomembrane with no defects (Fig. $3 a)$.

For this study, the thickness of samples is determined using a mechanical thickness gage that is similar to the gages described in ASTM Test Method for Measuring Nominal Thickness of Geotextiles and Geomembranes (D 5199). The average of the thickness measured at all of the measurement locations on an intact sample is recorded as the reference thickness value for the sample, referred to as $T B$ (thickness before). Next, ultrasonic data are collected at each measurement location. The transducer is placed and lifted four times at each location to obtain four waveforms. Each waveform consists of the average of 10 signals recorded during a single placement of the transducer. The average of these measurements is used as the ultrasonic reading for that location. The ultrasonic travel time and mechanical thickness measured at each location are used to calculate a velocity for the measurement location. The average of the velocities determined at all of the measurement locations on the intact sample is recorded as the reference ultrasonic velocity for the sample, referred to as $V B$ (velocity before). Energy for each measurement location is also determined using the four wave-forms. The average of the energies measured at all of the measure-ment locations is recorded as the reference waveform energy for the intact sample, referred to as $E B$ (energy before). Essentially, there is one $T B$, one $V B$, and one $E B$ for each sample.

In this study, ultrasonic measurements are repeated at the same locations as the initial measurements subsequent to degradation. Similar to initial ultrasonic measurements, four waveforms are recorded at each location and the average of these measurements is used as the ultrasonic reading for that location. The travel time measured at each location is used together with $V B$ for the sample to calculate a thickness value for the measurement location. The generated thickness value for each measurement location is referred to as $T A$ (thickness after). Comparison of $T A$ with $T B$ (average reference value for the intact geomembrane) is used to identify damage to the geomembrane. In addition, for samples with surface and internal defects, energy measurements are conducted. Energy for a particular measurement location is determined as the average of the energies obtained using the four waveforms, referred to as $E A$ (energy after). Comparison of $E A$ with $E B$ (average reference value for the intact geomembrane) is used to evaluate the geomembrane. Initially, comparisons are made between thickness measurements. If defects cannot be identified with thickness measurements, energy measurements are used.

The comparisons between thickness (TBand $T A$ ) and energy ( $E B$ and $E A$ ) measurements are made using student's t-statistics. A t-test is conducted to assess similarity of sample populations. The t-test consists of computing the difference between two sample means and then determining whether this difference is significant at a specified significance level, a, (Cheeney 1983). If the difference is significant, which indicates that the two compared values do not 
belong to the same population, the computed t-statistic $(|t|)$ is higher than a critical $t(t c r)$ at the specified significance level. Dif-ferent values of the significance level correspond to different con-fidence intervals. A significance level of 0.05 corresponding to a 95\% confidence interval is used in this study. When the difference between the measurement on the geomembrane sample and the ref-erence measurement is not significant $(|\mathrm{t}|<t \mathrm{cr})$, the geomembrane is deemed intact. When the difference between the measurement on the geomembrane sample and the reference value is significant $(|t|$ $>t \mathrm{cr}$ ), the geomembrane is deemed defective.

Thickness and velocity are dependent parameters; if one is known, the other can be calculated. Extensive testing was conducted to determine P-wave velocities of geomembranes. The tests indicated that the variation of P-wave velocity for geomembranes was very low. The coefficient of variation (COV) was less than $0.3 \%$ for the geomembranes used in this study. In addition, tests were conducted at a manufacturing facility on HDPE and LLDPE geomembranes. Velocity measurements were made on specimens, which were used for routine quality control testing of the manufactured rolls including physical, mechanical, and microstructural tests. The COV was less than $0.2 \%$ for these tests. Based on visual observation of the recorded waveforms, it is believed that the vari-ation in energy was also low both for the geomembranes used in the study and the geomembranes tested at the manufacturing facility. However, calculations have not been made for energy.

Preliminary testing can be conducted to determine the velocities and energies for geomembranes. The parameters $V B$ and $E B$ can be established for a geomembrane type (specific manufacturer, specific polymer, specific density). For evaluation of the particular type of geomembrane, ultrasonic measurements can be conducted on the intact geomembrane, and $T B$ can be calculated using previously determined $V B$ for the geomembrane and the travel time measured in the ultrasonic tests. The $E B$ can be determined from the ultrasonic tests on the intact geomembrane, or predetermined values for the particular geomembrane type can be used. Subsequent to use, ultrasonic measurements can be conducted on the geomem-brane. The TAcan be obtained using the predetermined $V B$ for the geomembrane and the travel time measured in the ultrasonic tests. The $E A$ can be determined using the waveforms obtained in the ultrasonic tests. For assessment of the condition of the geomembrane after use, the TBand EBcan be compared to the TAand $E A$ determined at the same or different locations on the geomembrane.

The steps of the test procedure can be summarized as:

1. Determine $T B$ and $E B$ for an intact geomembrane prior to use. Thickness for an intact geomembrane $(T B)$ is determined by averaging the thicknesses determined at all of the measurement locations on the geomembrane. The $T B$ can be determined using mechanical measurement or ultrasonic measurements with pre-determined values of velocity (eliminating mechanical measurements) for the test geomembrane. The waveform energy $(E B)$ for the intact geomembrane is de-termined by averaging the energies determined at all of the measurement locations on the geomembrane. Pre-determined values for $E B$ can be used directly as well without conducting ultrasonic tests.

2. Determine TAand $E A$ for each measurement location on a geomembrane subsequent to use by conducting ultrasonic measurements. Travel time measured on the used geomem-brane 
and VBare employed to calculate the thickness of the geomembrane $(T A)$ at each measurement location. Energy of the waveforms $(E A)$ for each location is also determined us-ing the waveforms recorded in the ultrasonic tests.

3. First, $T B$ and $T A$ and then, if needed, $E B$ and $E A$ are compared using a t-test for each measurement location. The analysis is completed when damage is identified. If damage is not iden-tified, this indicates that the geomembrane is not damaged at the particular measurement location.

\section{Materials}

Tests were conducted on 17 samples obtained from five types of unreinforced geomembranes (Table 1): high density polyethylene (HDPE), linear low density polyethylene (LLDPE), polyvinyl chloride (PVC), polypropylene (PP), and ethylene propylene diene monomer (EPDM).

\section{Testing Program}

Tests were conducted in the laboratory to determine the effec-tiveness of the ultrasonic test procedure to assess condition of geomembranes. Initially, measurements were obtained on intact geomembrane samples. The samples were then damaged and mea surements were repeated on the same locations as the initial measurements.

The samples and damage mechanisms used in the tests are listed in Table 2. In most cases, rectangular samples were used for the tests. A grid was drawn on these samples and measurements were taken at the intersection points on the grid. For grinding, burning, scratching, opening holes, and puncturing mechanisms, some of the measurement locations were damaged. For layering, and tensile elongation mechanisms, all of the measurement locations were damaged. Circular samples were used for the exposure tests. Only one measurement was made at the center of these sam-ples, and they were entirely exposed to the degradation mechanisms.

Defects were induced by nine mechanisms, which simulate installation damage mechanisms and in-service damage and degradation mechanisms that are expected to occur in the field. The defects were induced by grinding, burning, scratching, opening holes, puncturing, layering, tensile elongation, exposure to UV light, and exposure to chemicals:

\section{Grinding}

Grinding consisted of rubbing one surface of the geomembrane samples against a belt sander. The belt sander damaged one surface of the geomembranes, reducing the thickness of the samples. The heat generated during the process also caused changes in the microstructure of the samples. Measurements were conducted on the top (undamaged) surface of the samples. The damage was not vis-ible from this surface.

\section{Burning}

Samples were burned by the flame of a lighter until a spark indicating the ignition of the geomembrane was observed. The flame was extinguished before the defect penetrated the entire thickness of a sample. Damage to the samples was visible from both surfaces of the samples. Measurements were conducted on the top surface of the samples. 


\section{Scratching}

A utility knife was used to scratch the geomembranes. An area of approximately $100 \mathrm{~mm} 2$ on each measurement location was scratched by etching a fine grid with the knife. Intervals between scratch marks varied between 1 to $5 \mathrm{~mm}$. Length of the scratch marks was approximately $10 \mathrm{~mm}$. Depth of the scratches was ap-proximately 5 to $50 \%$ of the thickness of the samples. The scratches were not visible from the bottom surface of the samples. Measurements were taken both on top (scratched) and bottom (unscratched) surface of the samples.

\section{Opening Holes}

A thin steel needle with a diameter of $0.6 \mathrm{~mm}$ was used to open holes which penetrated the entire thickness of the geomembranes. A single hole was made at each measurement location. Measurements were taken on top surface of the samples. The holes made in rigid geomembranes were not clearly visible, and the holes made in flexible geomembranes were not visible at all. Although these were very small holes, they conveyed water in most cases.

\section{Puncturing}

Samples were punctured by placing them over a 50-mm-thick layer of angular gravel confined in a steel ring. The samples were held in place under pressure for $24 \mathrm{~h}$. Permanent deformation of the geomembranes was visible on both sides of the samples, although, in most cases, the gravel did not puncture through the entire thick-ness of the samples. Measurements were taken on top surface of the samples.

\section{Layering}

Samples thicker than $1.5 \mathrm{~mm}$ were cut horizontally along the underside using a circular toolhead mounted on a milling machine. This layering process decreased the thickness of the samples. Measurements were made on the top surface of the samples. The reduction in the thickness of samples was not visible from the top surface.

\section{Tensile Elongation}

Samples were elongated to 25\% strain in accordance with ASTM Test Method for Determining Performance Strength of Geomembranes by the Wide Strip Tensile Method (D 4885). Ultrasonic tests were conducted at this strain while the samples were held by the grips in the testing machine. Measurements were obtained at only twelve locations on the tensioned samples, due to difficulties encountered in keeping the transducer in contact with the samples in the test machine. An additional PVC sample was tested at $10 \%$ strain to investigate the capability of the ultrasonic method to detect changes in thickness at lower strain levels.

\section{Exposure Tests}

For UV light exposure tests, geomembranes were exposed to a UV-B lamp with $254 \mathrm{~nm}$ wavelength and 40 watt intensity for 60 days. For chemical exposure tests, acetone and toluene were used. Samples were immersed in the chemicals for 180 days. Pure chemicals were used to accelerate the degradation of geomembranes. 


\section{Results}

Thickness and energy were used to evaluate the samples (Table 3). Changes in thickness measurements indicate changes in the thickness of the samples (e.g., due to grinding or layering) and also alteration of the microstructure and, thus, the velocity of the samples (e.g., due to burning or chemical exposure). Changes in energy measurements indicate the presence of surficial or internal defects (e.g., scratches or holes). Comparisons of $T B$ and $T A$ were used to identify defects induced by grinding, burning, scratching (measurements from the bottom surface), opening holes (in rigid geomembranes), layering, tensile elongation, UV light exposure, and chemical exposure. Comparisons of $E B$ and $E A$ were used to identify defects induced by scratching (measurements from the top surface), puncturing, and opening holes (in flexible geomembranes).

Scratches caused generation of extra reflections between the top and bottom surface reflections that were detected by the energy measurements when the tests were conducted on the top (scratched) surface of the samples. For the tests conducted on the bottom (unscratched) surface of the samples, scratches caused changes in the travel path and, thus, the travel time, which were identified by the thickness measurements. Although opening holes did not change the thickness of the samples, the travel time of the P-waves changed in rigid geomembranes containing holes. It is believed that the waves traveled partly through the geomembranes and partly through the water couplant collected in the holes. This increased the travel time of the waves, as the wave velocity in water is lower than the wave velocity in geomembranes. For flexible geomembranes, presence of the holes caused extra reflections in the waveforms, which were identified by energy measurements.

Measurements made on intact and damaged geomembrane sam-ples were compared to assess damage to the geomembranes. An example of a t-test conducted on an LLDPE sample subjected to grinding is presented in Table 4. Thickness measurements made on the sample before and after grinding are presented in Fig. 5. All of the damaged locations were identified by the ultrasonic measure-

ments. Results of thickness measurements for samples degraded by grinding, burning, scratching (measurements from the bottom sur-face), opening holes (rigid geomembranes), layering, and tensile elongation are presented in Fig. 6 ( $a$ through $f$ ). Results of energy measurements for samples degraded by scratching (measurements from the top surface), puncturing, and opening holes (flexible geomembranes) are presented in Fig. 7 ( $a$ through $c$ ). Exposure tests are presented in Fig. 8 ( $a$ through $c$ ). Results for a total of five sam-ples (one sample from each geomembrane type) are shown in these figures. Results for the remaining samples, and individual t-tests for each sample, were reported by Sungur (1999).

An example of the use of predetermined ultrasonic parameters is presented in Fig. $6 a$. The velocity, VB2, previously established for the PP tested in the study, was used with ultrasonic travel time mea-surements obtained on the intact sample presented in Fig. $6 a$ at each test location to determine the thickness for the location. The average of all the thicknesses for all the measurement locations was recorded as TB2 for the sample. Subsequent to damage, ultrasonic measurements were made on the sample, and the measured travel times were used with $V B 2$ to determine TA2. In this case, mechani-cal thickness measurements were not used. The results obtained from the comparison of TB2 and $T A 2$ were similar to the results ob-tained from the comparison of TB1(obtained 
using mechanical measurements) and TA1(obtained using VB1established for the particular test sample), TB1(obtained using mechanical measure-ments), and TA1 (obtained using VB1established for the particular test sample) and all of the damaged locations were detected in both cases (Fig. $6 a$ ). Also, it was observed that TB1and $T B 2$ and TA1and TA2were very similar (Fig. $6 a$ ).

For puncturing, it was observed that the "damaged" locations did not necessarily match the intersection points on the grids. Some of the locations (Nos. 14 and 15 on LLDPE, Nos. 5 and 12 on PP) that were intended to be "damaged" were actually "undamaged," and they were not detected by the method (Fig. $7 b$ ). Visual observations of these locations did not indicate "damage" to the samples. Mechanical thickness measurements subsequent to puncturing also did not give any indication of change in the thickness. Ultrasonic measurements after puncturing at these locations did not indicate any change either, and consequently, these locations were not de-tected as damaged locations using the test procedure.

Results of the statistical analysis indicate that defects generated by the mechanisms used in this study can be identified using the ul-trasonic method. There were significant differences between the "before" and "after" measurements for all of the samples damaged by grinding, burning, scratching (measurements from the bottom surface), layering, tensile elongation (both at 10\% and 25\% strain), and puncturing mechanisms (Sungur 1999). The large differences in the measurements for intact and damaged locations for these mechanisms are shown in Figs. 6 and $7 b$.

There were few exceptions to the effectiveness of the ultrasonic method for samples damaged by scratching (measurements from the top surface) and opening holes. In Fig. $7 a$, presence of scratches was identified with the exceptions of one measurement location (No. 13) on the LLDPE sample and two measurement locations (Nos. 15 and 16) on the PP sample. It was observed that the depth of the scratches at these locations was very small, and hence, they did not cause significant changes in the energy measurements. In Fig. $6 d$, presence of holes at measurement locations 12,13 , and 15 were not identified, and the intact measurement location 17 was identified as "damaged" for the LLDPE sample. Measurement locations 9 and 10 were not identified as "damaged" for the PP sam-ple, and measurement locations 12 and 16 were not identified as "damaged" for the EPDM sample (Fig. $7 c$ ). It is believed that this resulted from the very small dimensions of the holes, which did not cause significant changes in the ultrasonic measurements. The total number of similar exceptions was less than $2 \%$ of all of the measurements made for the entire testing program (Sungur 1999).

Effects of exposure mechanisms were variable on different types of geomembranes. In addition to ultrasonic tests, physical characteristics (weight, diameter, and specific gravity) and microstructural properties (crystallinity and melting temperature for PE and PP) of the samples were determined. Results of the ultrasonic tests were compared with the results of physical and microstructural tests to verify the effectiveness of the ultrasonic method.

The geomembranes used in the tests were not affected significantly by UV light exposure (Fig. 8a). This resulted from the short exposure period and relatively low intensity of the UV lamp. Vari- ation in color and appearance was observed for PVC and PP sam-ples. However, these changes were not reflected in the ultrasonic measurements or the physical 
and microstructural tests. Changes in ultrasonic velocity were less than $6 \%$. Changes in weight, diameter, and specific gravity of the samples were less than $3 \%$, with the exception of $17 \%$ variation in the specific gravity for the EPDM sample. Changes in melting temperature and degree of crystallinity of the samples were less than $3 \%$ and $7 \%$, respectively.

For the chemical exposure tests (Fig. 8b,c and Table 5), it was observed that PVC samples were significantly affected by immer-sion in acetone, and PP and EPDM samples were significantly affected by immersion in toluene. Polyethylene samples were less affected by the chemicals than PVC, PP, and EPDM samples. It is believed that determination of specific gravity and microstructural properties of the samples could be less reliable than determination of weight and dimensions of the samples, due to evaporation of the chemicals after removal of the samples from test containers. Also, potential interactions between water and the exposed samples dur-ing specific gravity tests could have affected the results.

\section{Potential Field Use of the Ultrasonic Method}

The electronic equipment used in the test program can be adapted easily for field testing. Thickness and velocity measurements can be conducted using the transducer and the handheld thickness gage without the digital oscilloscope. The digital oscilloscope is needed only for the energy measurements, and a laptop computer can be used for conducting tests in the field (a laptop computer was used during the tests conducted at the manufacturing facility). Essentially, the equipment required consists of a trans ducer, a pulser-receiver, and a data acquisition system, and various portable ultrasonic setups are available that can be adapted easily for field testing of geomembranes. Water can be used as the coupling material in the field for flat surfaces. Commercially available ultrasonic couplants (with gellike consistencies), or materials such as petroleum jelly and honey, can be used at slopes and near vertical orientations.

The method described in this paper is based on a comparison of ultrasonic measurements obtained on a potentially damaged geomembrane to measurements obtained from an intact geomembrane. Baseline ultrasonic parameters can be established for geomembranes and used as measurements for intact conditions for comparison to measurements on used geomembranes. Thickness, which is the parameter required for the method, can be determined using mechanical measurements or obtained using only ultrasonic measurements. The method can be used to determine damage to geomem-branes after use, or used as part of a monitoring program to assess the condition of geomembranes in time. Repeated measurements can be made in time at the same location on a geomembrane using this method. Since a small area is covered in each ultrasonic measurement, the method is most applicable to potential problem areas. However, it is possible to develop arrays containing several sensors and conduct measurements at multiple locations at a time, increas-ing the capacity of the method.

For a field application, three procedures can be used: (1) measurements can be conducted at certain locations and repeated at the same or different locations after field use, (2) measurements can be made on coupons removed from a geomembrane prior to installa-tion and at various locations on the geomembrane after field use, and (3) for a geomembrane for which no prior measurements exist, comparisons can be made to a similar geomembrane (produced by the same manufacturer, similar polymer, similar density). 
Alterna-tively, if coupons of the original geomembrane were saved, ultra-sonic measurements can be conducted on the coupons and used for comparison.

\section{Summary}

An ultrasonic test method was used to assess the condition of geomembranes. The pulse-echo inspection technique was used on the surface of geomembranes without disturbing the material. Travel time of ultrasonic waves and waveform energy was measured to evaluate the condition of geomembranes. The equipment required consists of a Pwave transducer, a pulser-receiver, and a signal acquisition system. Various alternatives for test setups are available for laboratory and field testing.

Laboratory tests were conducted on five types of geomembranes (HDPE, PVC, PP, LLDPE, and EPDM) to assess the effectiveness of the method. Defects and degradation conditions were induced by nine mechanisms that were expected to occur in the field, due to common installation practices and operating conditions. Measure-ments taken on intact and damaged geomembrane samples were compared using student's t-statistics to evaluate the condition of the geomembranes. The defects were identified with the ultrasonic method at a success rate higher than $98 \%$. Changes in the thickness or the microstructure of the geomembranes were identified. Defects that were on the surface of the samples, and also defects that were on the underside of the samples (not visible from the measurement surface), were detected. In addition, defects that penetrated the entire thickness of the samples were identified. Furthermore, effects of UV light and chemical degradation were assessed using the ultrasonic measurements. These measurements were compared with physical and microstructural tests. The results of the ultrasonic and physical and microstructural tests agreed well for the samples degraded by UV light or chemical exposure. This method shows promise for monitoring the condition of geomembranes in the laboratory, or in the field, over time by conducting repeated measurements, and for assessing in situ damage to geomembranes.

\section{Acknowledgment}

Financial support for this study was provided by the National Science Foundation (NSF Grant No: CMS 97-01947). Mr. Gna-natilake Gamage assisted in the testing program. Materials were supplied by National Seal Co. (Mr. John Siebken's assistance is ap-preciated), GSE Lining Technology Inc., HPG International Inc., Serrot Corp. (Mr. Ted Fox's assistance is appreciated), Staff In-dustries Inc., Firestone Inc., and JPS Elastomerics Corp.

\section{References}

Bonaparte, R. and Gross, B. A., 1990, “Field Behavior of Double-Liner Systems,” Waste Containment Systems: Construction, Regulation, and Performance, Geotechnical Special Publication No. 26, R. Bonaparte, Ed., American Society of Civil Engineers, New York, NY, pp. 52-83.

Bray, D. E. and McBride, D., 1992, Nondestructive Testing Tech-niques, D. E. Bray and D. McBride, Eds., Wiley \& Sons Inc., New York, NY.

Cheeney, R. F., 1983, Statistical Methods in Geology, George Allen \& Unwin (Publishers) Ltd., London, UK.

Comer, A., Kube, M., and Sayer, K., 1996, "Remediation of Existing Canal Linings," Geotextiles and Geomembranes, Elsevier, London, UK, Vol. 14, pp. 3 13-325. 
Darilek, G., Laine, D., and Parra, J. O., 1989, “The Electrical Leak Location Method for Geomembrane Liners: Development and Applications," Proceedings of Geosynthetics '89 Conference, Industrial Fabrics Association International, St. Paul, MN, pp. 456-462.

Darilek, G., Menzel, R., and Johnson, A., 1995, "Minimizing Geo-membrane Liner Damage While Emplacing Protective Soil," Proceedings of Geosynthetics '95 Conference, Industrial Fabrics Association International, St. Paul, MN, pp. 669-676.

Fisher, G. E., 1989, “Controlling Thermal Damage in Flexible Membrane Liners,” Geotechnical Fabrics Report, March/April, Industrial Fabrics Association International, St. Paul, MN, pp. 39-41.

Giroud, J. P., Beech, J. F., and Soderman, K. L., 1994, "Yield of Scratched Geomembranes," Geotextiles and Geomembranes, Elsevier, London, UK, Vol. 13, pp. 23 1-246.

Green, R. E., Jr., 1987, “Ultrasonic Nondestructive Materials Char-acterization,” Materials Analysis by Ultrasonics, A. Vary, Ed., Noyes Data Corporation, Park Ridge, NJ, pp. 1-29. Koerner, R. M., 1998, Designing with Geosynthetics, Prentice-Hall, Upper Saddle River, NJ. Laine, D. L. and Mosley, N. G., 1993, "Leak Location Survey of a Soil Covered Geomembrane at a Landfill Site in the UK,” Waste Disposal by Landfill - GREEN'93, R. W. Sarsby, Ed., Balkema, Brookfield, VT, pp. 151-156.

McIntire, P., 1991, Nondestructive Testing Handbook, Volume Seven, Ultrasonic Testing, American Society for Nondestructive Testing, Columbus, $\mathrm{OH}$.

Park, J. K., Sakti, J. P., and Hoopes, J. A., 1995, “Effectiveness of Geomembranes as Barriers for Organic Compounds," Proceed-ings of Geosynthetics '95 Conference, Industrial Fabrics Association International, St. Paul, MN, pp. 879-892.

Peggs, I. D., 1988, “Failure and Repair of Geomembrane Lining Systems," Geotechnical Fabrics Report, November, Industrial Fabrics Association International, St. Paul, MN, pp. 13-16.

Peggs, I. D., 1993, "Practical Geoelectric Leak Surveys with Hand-Held and Remote and Water Lance Probes," Proceedings of Geosynthetics '93 Conference, Industrial Fabrics Association International, St. Paul, MN, pp. 1523-1532.

Peggs, I. D. and Carlson, D. S., 1989, "Stress Cracking of Polyethylene Geomembrane: Field Experience," Geotextiles and Geomembranes, Elsevier, London, UK, May, pp. 195211.

Peggs, I. D. and Carlson, D. S., 1990, "The Effects of Seaming on the Durability of Adjacent Polyethylene Geomembranes," Geosynthetic Testing for Waste Containment Applications, ASTM STP 1081, R. M. Koerner, Ed., American Society for Testing and Materials, Philadelphia, PA, pp. 132-142.

Steffen, H. and Asmus, D. B., 1993, "Geomembrane Sealing of a Waste Disposal Area, Mechernich/Euskirchen, Germany," Geosynthetics Case Histories, G. P. Raymond and J. P. Giroud, Eds., BiTech Publishers Ltd., Canada, pp. 34-35.

Sungur, S., 1999, "Evaluation of Geomembranes Using Ultrasonic Pulse-Echo Technique," Master of Science Thesis, Department of Civil and Environmental Engineering, Wayne State University, Detroit, MI. 


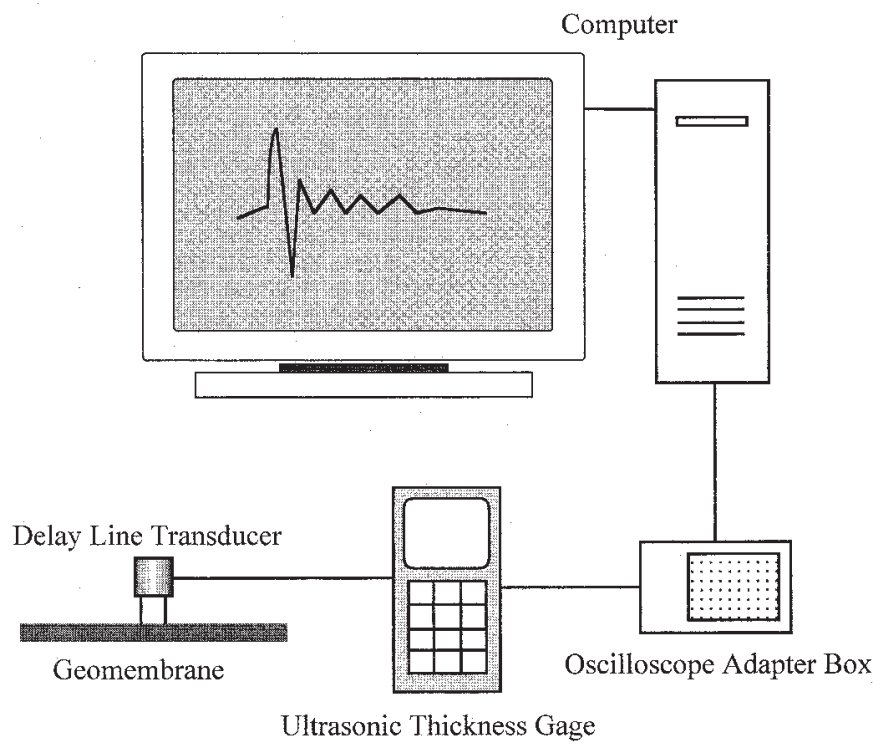

FIG. 1-Ultrasonic test system used in the study.
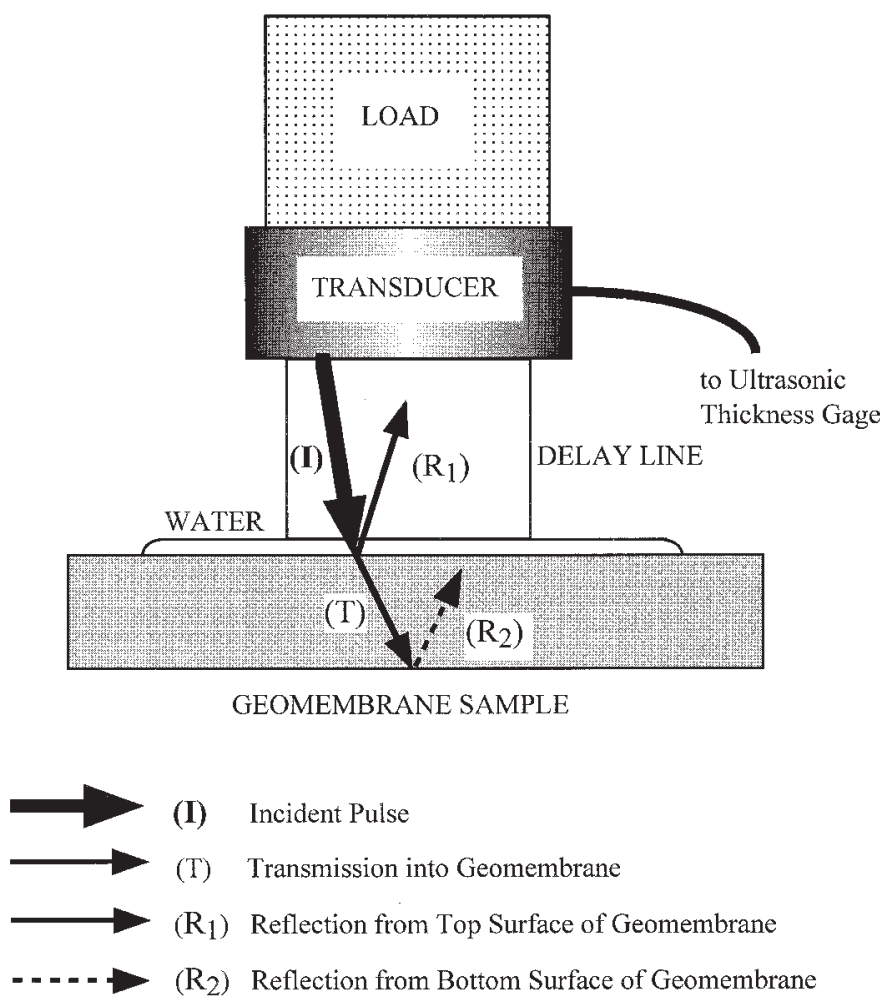

FIG. 2-Wave sequences generated in the tests. 


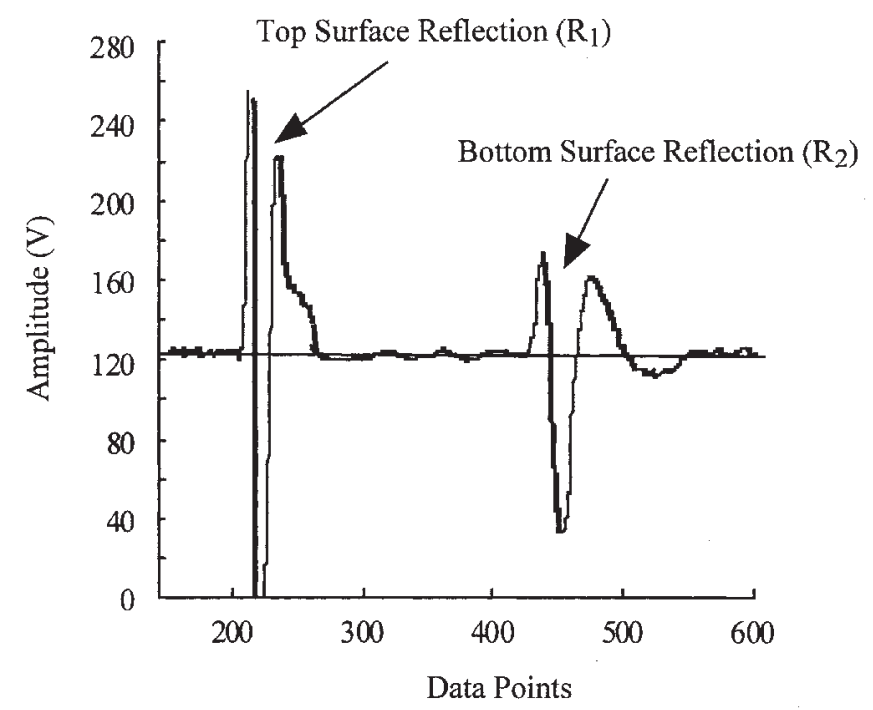

FIG. 3a-Typical waveform for an intact geomembrane.

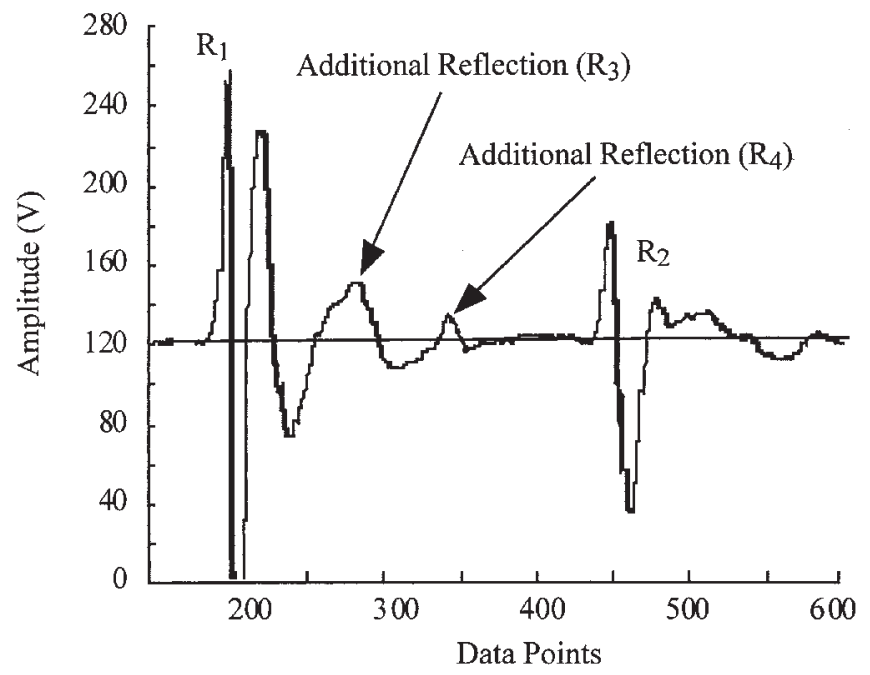

FIG. 3b—Typical waveform for a scratched geomembrane.
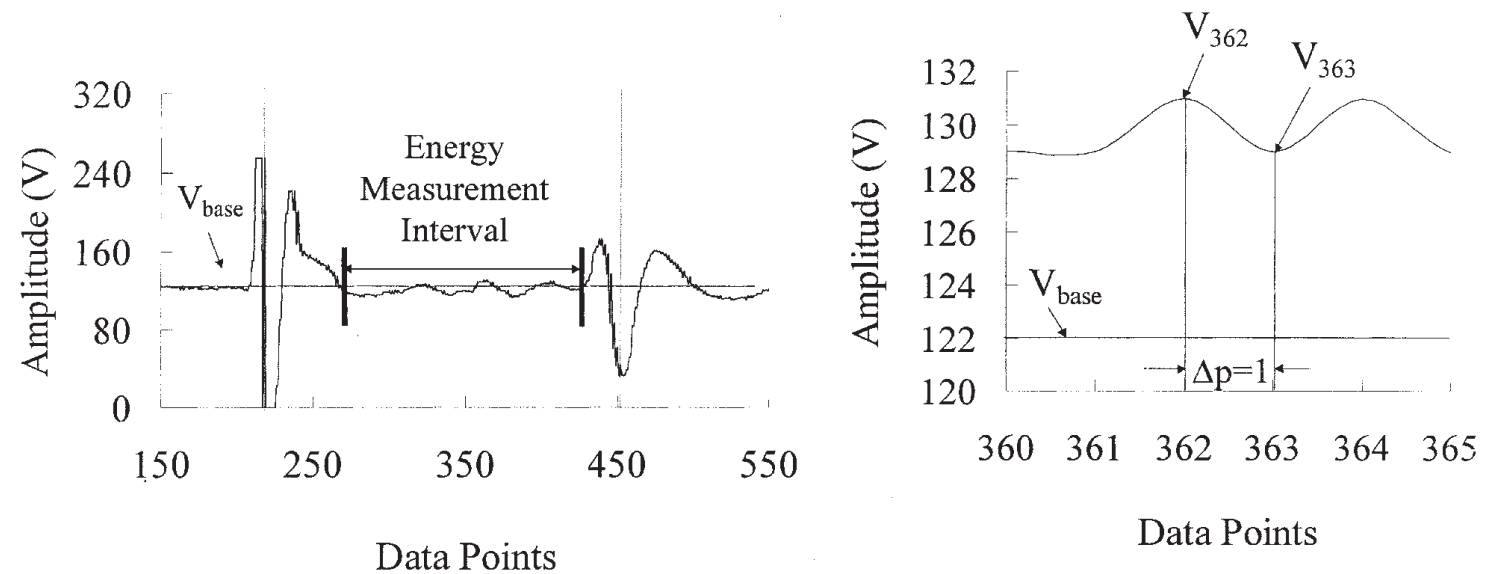

FIG. 4-Determination of waveform energy. 
TABLE 1-Geomembranes used in the study.

\begin{tabular}{ccc}
\hline $\begin{array}{c}\text { Geomembrane } \\
\text { Type }\end{array}$ & Sample & $\begin{array}{c}\text { Nominal Thickness, } \\
\text { mm }\end{array}$ \\
\hline \multirow{2}{*}{ HDPE } & A1-60 & 1.5 \\
& A2-60 & 1.5 \\
& A3-60 & 1.5 \\
& B1-100 & 2.5 \\
B2-60 & 1.5 \\
PVC & B3-40 & 1.0 \\
& C1-40 & 1.0 \\
& C2-60 & 1.5 \\
& C3-40 & 1.0 \\
PP & C4-40 & 1.0 \\
& C5-40 & 1.0 \\
LLDPE & D1-40 & 1.0 \\
& E1-40 & 1.0 \\
EPDM & F1-40 & 0.9 \\
& G1-30 & 0.8 \\
& G2-60 & 1.5 \\
& H1-60 & 1.5 \\
\hline
\end{tabular}

TABLE 2-Samples and damage mechanisms.

\begin{tabular}{lcl}
\hline & $\begin{array}{c}\text { Sample } \\
\text { Dimensions, } \\
\text { mm }\end{array}$ & Area Damaged \\
\hline Grinding & $200 \times 100$ & $16 / 28$ Locations \\
Burning & $200 \times 100$ & $16 / 28$ Locations \\
Scratching & $200 \times 100$ & $16 / 28$ Locations \\
Opening Holes & $200 \times 100$ & $16 / 28$ Locations \\
Puncturing & $300 \times 200$ & $16 / 28$ Locations \\
Layering & $110 \times 90$ & $28 / 28$ Locations \\
Tensile Elongation & $240 \times 200$ & $12 / 12$ Locations \\
Exposure to UV Light & $\emptyset 41$ & $1 / 1$ Location \\
Exposure to Chemicals & $\varnothing 41$ & $1 / 1$ Location \\
\hline
\end{tabular}

TABLE 3-Measurements used to detect defects in test samples.

\begin{tabular}{|c|c|c|c|c|c|c|c|c|c|c|c|}
\hline $\begin{array}{c}\text { Geomembrane } \\
\text { Type }\end{array}$ & Sample & $G^{1}$ & $B^{3}$ & $S^{3}$ & $S^{3 *}$ & $O H^{4}$ & $P^{5}$ & $L^{6}$ & $T E^{7}$ & $U V L^{8}$ & $C E^{9}$ \\
\hline \multirow[t]{6}{*}{ HDPE } & A1-60 & $T_{B} / T_{A}$ & $T_{B} / T_{A}$ & $E_{B} / E_{A}$ & & & $E_{B} / E_{A}$ & $T_{B} / T_{A}$ & & $T_{B} / T_{A}$ & $T_{B} / T_{A}$ \\
\hline & A2-60 & $T_{B} / T_{A}$ & $T_{B} / T_{A}$ & $E_{B} / E_{A}$ & & & $E_{B} / E_{A}$ & $T_{B} / T_{A}$ & & $T_{B} / T_{A}$ & $T_{B} / T_{A}$ \\
\hline & A3-60 & $T_{B} / T_{A}$ & $T_{B} / T_{A}$ & $E_{B} / E_{A}$ & & & $E_{B} / E_{A}$ & $T_{B} / T_{A}$ & & $T_{B} / T_{A}$ & $T_{B} / T_{A}$ \\
\hline & B1-100 & $T_{B} / T_{A}$ & $T_{B} / T_{A}^{A}$ & $E_{B} / E_{A}$ & & & $E_{B} / E_{A}$ & $T_{B} / T_{A}$ & & $T_{B} / T_{A}$ & $T_{B} / T_{A}^{A}$ \\
\hline & B2-60 & $T_{B} / T_{A}$ & $T_{B} / T_{A}$ & $E_{B} / E_{A}$ & & & $E_{B} / E_{A}$ & & $T_{B} / T_{A}$ & $T_{B} / T_{A}$ & $T_{B} / T_{A}$ \\
\hline & B3-40 & $T_{B} / T_{A}$ & $T_{B} / T_{A}$ & $E_{B} / E_{A}$ & $T_{B} / T_{A}$ & $T_{B} / T_{A}$ & $E_{B} / E_{A}$ & & $T_{B} / T_{A}$ & $T_{B} / T_{A}$ & $T_{B} / T_{A}$ \\
\hline \multirow[t]{5}{*}{ PVC } & C1-40 & $T_{B} / T_{A}$ & $T_{B} / T_{A}$ & $E_{B} / E_{A}$ & & $E_{B} / E_{A}$ & $E_{B} / E_{A}$ & & $T_{B} / T_{A}$ & $T_{B} / T_{A}$ & $T_{B} / T_{A}$ \\
\hline & C2-60 & $T_{B} / T_{A}$ & $T_{B} / T_{A}$ & $E_{B} / E_{A}$ & & $E_{B} / E_{A}$ & $E_{B} / E_{A}$ & & $T_{B} / T_{A}$ & $T_{B} / T_{A}$ & $T_{B} / T_{A}$ \\
\hline & C3-40 & $T_{B} / T_{A}$ & $T_{B} / T_{A}$ & $E_{B} / E_{A}$ & & $E_{B} / E_{A}$ & $E_{B} / E_{A}$ & & & $T_{B} / T_{A}$ & $T_{B} / T_{A}$ \\
\hline & C4-40 & $T_{B} / T_{A}$ & $T_{B} / T_{A}$ & $E_{B} / E_{A}$ & & $E_{B} / E_{A}$ & $E_{B} / E_{A}$ & & & $T_{B} / T_{A}$ & $T_{B} / T_{A}$ \\
\hline & C $5-40$ & $T_{B} / T_{A}$ & $T_{B} / T_{A}$ & $E_{B} / E_{A}$ & & $E_{B} / E_{A}$ & $E_{B} / E_{A}$ & & & $T_{B} / T_{A}$ & $T_{B} / T_{A}$ \\
\hline \multirow[t]{3}{*}{ PP } & D1-40 & $T_{B} / T_{A}$ & $T_{B} / T_{A}^{A}$ & $E_{B} / E_{A}$ & & $E_{B} / E_{A}$ & $E_{B} / E_{A}$ & & $T_{B} / T_{A}$ & $T_{B} / T_{A}$ & $T_{B} / T_{A}^{A}$ \\
\hline & E1-40 & $T_{B} / T_{A}$ & $T_{B} / T_{A}$ & $E_{B} / E_{A}$ & & $E_{B} / E_{A}$ & $E_{B} / E_{A}$ & & & $T_{B} / T_{A}$ & $T_{B} / T_{A}$ \\
\hline & F1-40 & $T_{B} / T_{A}$ & $T_{B} / T_{A}$ & $E_{B} / E_{A}$ & & $E_{B} / E_{A}$ & $E_{B} / E_{A}$ & & $T_{B} / T_{A}$ & $T_{B} / T_{A}$ & $T_{B} / T_{A}$ \\
\hline \multirow[t]{2}{*}{ LLDPE } & G1-30 & $T_{B} / T_{A}$ & $T_{B} / T_{A}$ & $E_{B} / E_{A}$ & & $T_{B} / T_{A}$ & $E_{B} / E_{A}$ & & $T_{B} / T_{A}$ & $T_{B} / T_{A}$ & $T_{B} / T_{A}$ \\
\hline & G2 -60 & $T_{B} / T_{A}$ & $T_{B} / T_{A}$ & $E_{B} / E_{A}$ & & & $E_{B} / E_{A}$ & $T_{B} / T_{A}$ & $T_{B} / T_{A}$ & $T_{B} / T_{A}$ & $T_{B} / T_{A}$ \\
\hline EPDM & H1-60 & $T_{B} / T_{A}$ & $T_{B} / T_{A}$ & $E_{B} / E_{A}$ & & $E_{B} / E_{A}$ & $E_{B} / E_{A}$ & & $T_{B} / T_{A}$ & $T_{B} / T_{A}$ & $T_{B} / T_{A}$ \\
\hline
\end{tabular}

${ }^{1}$ Grinding, ${ }^{2}$ Burning, ${ }^{3}$ Scratching (measurements from top surface), ${ }^{3}$ Scratching (measurements from bottom surface), ${ }^{4}$ Opening Holes, ${ }^{5}$ Puncturing, ${ }^{6}$ Layering, ${ }^{7}$ Tensile Elongation, ${ }^{8}$ UV Light Exposure, ${ }^{9}$ Chemical Exposure. 
TABLE 4-Student's t-statistics for an LLDPE sample (G1-30) damaged by grinding.

\begin{tabular}{|c|c|c|c|c|c|c|}
\hline $\begin{array}{l}\text { Measurement } \\
\text { Locations }\end{array}$ & $\begin{array}{c}T_{B} \\
\mathrm{~mm}\end{array}$ & $\begin{array}{l}T_{A}, \\
\mathrm{~mm}\end{array}$ & $t$ & $T_{\mathrm{cr}}$ & $\mathbf{Y} / \mathbf{N}$ & Condition \\
\hline 1 & 0.812 & 0.697 & 7.83 & 2.04 & $\mathbf{Y}$ & Damaged \\
\hline 2 & 0.812 & 0.742 & 4.78 & 2.04 & $\mathbf{Y}$ & Damaged \\
\hline 3 & 0.812 & 0.746 & 4.50 & 2.04 & $\mathbf{Y}$ & Damaged \\
\hline 4 & 0.812 & 0.739 & 4.98 & 2.04 & $\mathbf{Y}$ & Damaged \\
\hline 5 & 0.812 & 0.772 & 2.74 & 2.04 & $\mathbf{Y}$ & Damaged \\
\hline 6 & 0.812 & 0.724 & 6.00 & 2.04 & $\mathbf{Y}$ & Damaged \\
\hline 7 & 0.812 & 0.771 & 2.81 & 2.04 & $\mathbf{Y}$ & Damaged \\
\hline 8 & 0.812 & 0.764 & 3.28 & 2.04 & $\mathbf{Y}$ & Damaged \\
\hline 9 & 0.812 & 0.698 & 7.77 & 2.04 & $\mathbf{Y}$ & Damaged \\
\hline 10 & 0.812 & 0.717 & 6.47 & 2.04 & $\mathbf{Y}$ & Damaged \\
\hline 11 & 0.812 & 0.763 & 3.35 & 2.04 & $\mathbf{Y}$ & Damaged \\
\hline 12 & 0.812 & 0.768 & 3.01 & 2.04 & $\mathbf{Y}$ & Damaged \\
\hline 13 & 0.812 & 0.766 & 3.15 & 2.04 & $\mathbf{Y}$ & Damaged \\
\hline 14 & 0.812 & 0.752 & 4.10 & 2.04 & $\mathbf{Y}$ & Damaged \\
\hline 15 & 0.812 & 0.716 & 6.54 & 2.04 & $\mathbf{Y}$ & Damaged \\
\hline 16 & 0.812 & 0.764 & 3.28 & 2.04 & $\mathbf{Y}$ & Damaged \\
\hline 17 & 0.812 & 0.804 & 0.57 & 2.04 & $\mathbf{N}$ & Intact \\
\hline 18 & 0.812 & 0.814 & 0.11 & 2.04 & $\mathbf{N}$ & Intact \\
\hline 19 & 0.812 & 0.813 & 0.05 & 2.04 & $\mathbf{N}$ & Intact \\
\hline 20 & 0.812 & 0.816 & 0.25 & 2.04 & $\mathbf{N}$ & Intact \\
\hline 21 & 0.812 & 0.827 & 1.00 & 2.04 & $\mathbf{N}$ & Intact \\
\hline 22 & 0.812 & 0.818 & 0.39 & 2.04 & $\mathbf{N}$ & Intact \\
\hline 23 & 0.812 & 0.824 & 0.79 & 2.04 & $\mathbf{N}$ & Intact \\
\hline 24 & 0.812 & 0.819 & 0.45 & 2.04 & $\mathbf{N}$ & Intact \\
\hline 25 & 0.812 & 0.822 & 0.66 & 2.04 & $\mathbf{N}$ & Intact \\
\hline 26 & 0.812 & 0.814 & 0.13 & 2.04 & $\mathbf{N}$ & Intact \\
\hline 27 & 0.812 & 0.812 & 0.02 & 2.04 & $\mathbf{N}$ & Intact \\
\hline 28 & 0.812 & 0.826 & 0.93 & 2.04 & $\mathbf{N}$ & Intact \\
\hline
\end{tabular}

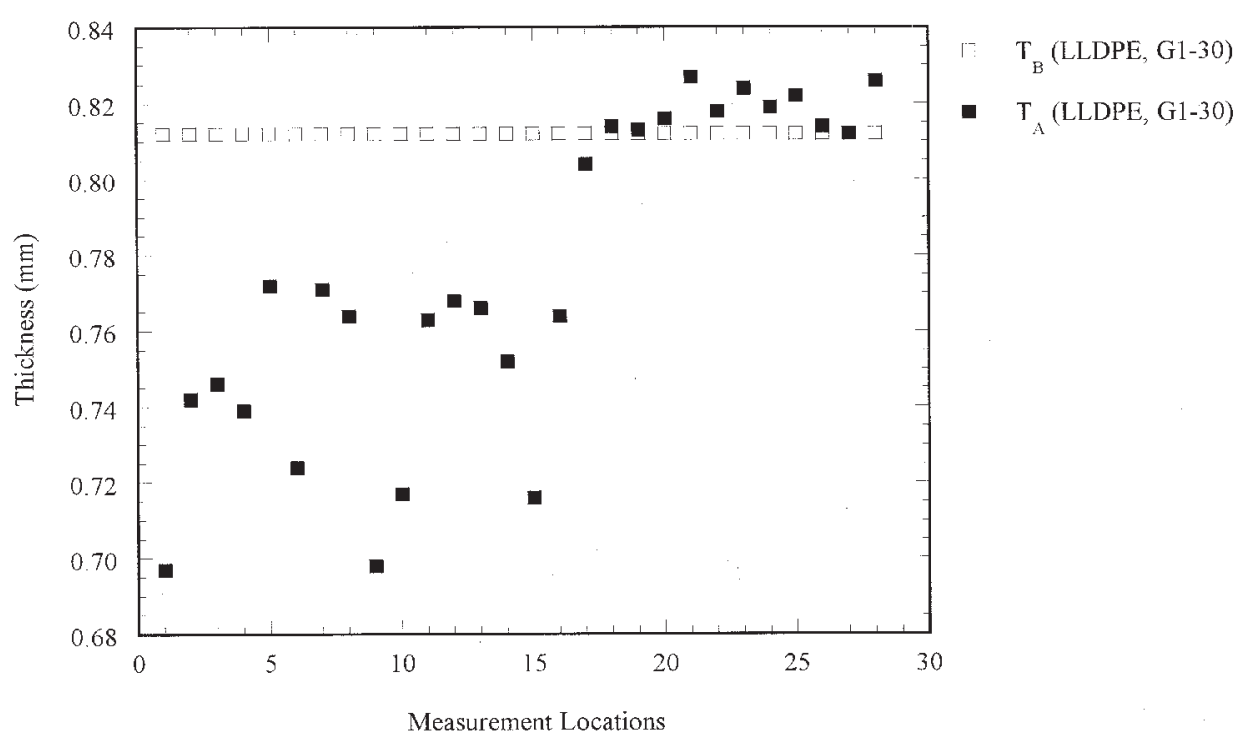

FIG. 5-An LLDPE sample damaged by grinding. 


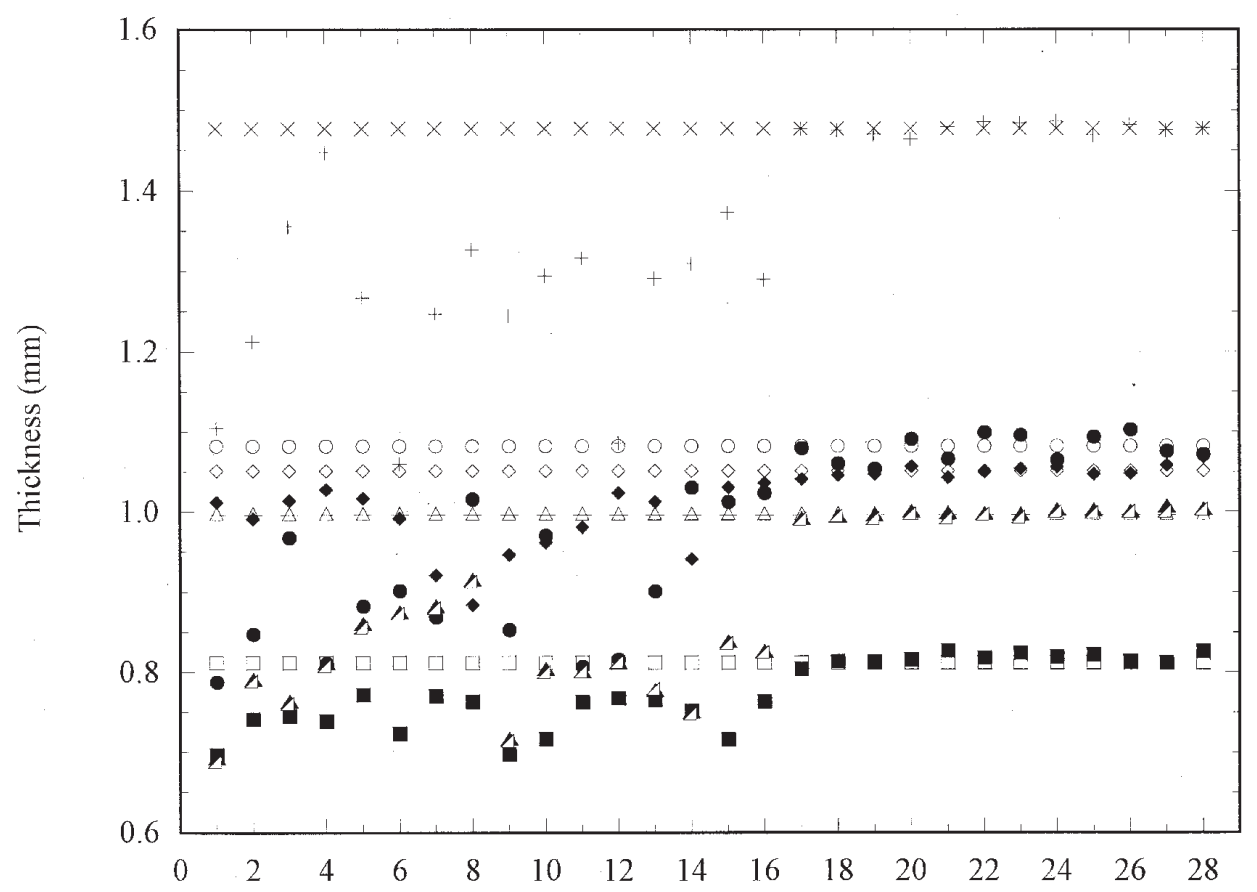

- $\mathrm{T}_{\mathrm{B}}$ (HDPE, B3-40)

- $\mathrm{T}_{\mathrm{A}}$ (HDPE, B3-40)

$\sqcup T_{B}$ (LLDPE, G1-30)

- $\mathrm{T}_{\mathrm{A}}$ (LLDPE, G1-30)

$\mathrm{T}_{\mathrm{B}}$ (PVC, $\mathrm{Cl}$-40)

- $\mathrm{T}_{\mathrm{A}}(\mathrm{PVC}, \mathrm{Cl}-40)$

$\mathrm{T}_{\mathrm{B} 1}(\mathrm{PP}, \mathrm{D} 1-40)$

- $\mathrm{T}_{\mathrm{A} 1}(\mathrm{PP}, \mathrm{D} 1-40)$

- $\mathrm{T}_{\mathrm{B} 2}(\mathrm{PP}, \mathrm{D} 1-40)$

$\triangle \quad \mathrm{T}_{\mathrm{A} 2}(\mathrm{PP}, \mathrm{D} 1-40)$

$\times \quad \mathrm{T}_{\mathrm{B}}(\mathrm{EPDM}, \mathrm{HI}-60)$

$\mathrm{T}_{\mathrm{A}}$ (EPDM, H1-60)

Measurement Locations

FIG. $6 a-S a m p l e s$ damaged by grinding.

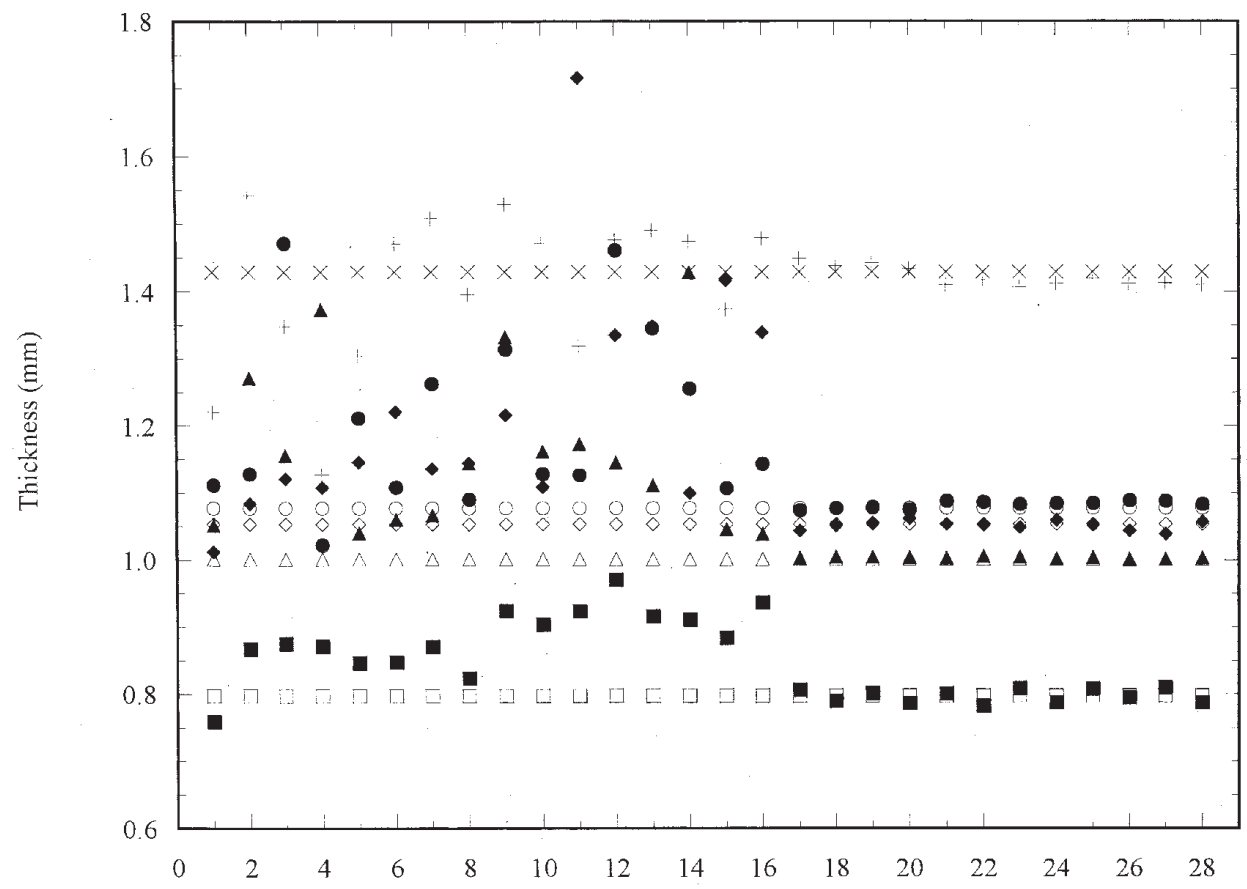

$T_{B}$ (HDPE, B3-40)

- $\mathrm{T}_{\mathrm{A}}$ (HDPE, B3-40)

$\exists \quad \mathrm{T}_{\mathrm{B}}$ (LLDPE, G1-30)

- $\mathrm{T}_{\mathrm{A}}$ (LLDPE, G1-30)

$\diamond \quad \mathrm{T}_{\mathrm{B}}$ (PVC, C1-40)

- $\mathrm{T}_{\mathrm{A}}(\mathrm{PVC}, \mathrm{Cl}-40)$

$\triangle \quad \mathrm{T}_{\mathrm{B}}(\mathrm{PP}, \mathrm{Dl}-40)$

$\triangle \quad \mathrm{T}_{\mathrm{A}}(\mathrm{PP}, \mathrm{DI}-40)$

$\times \quad \mathrm{T}_{\mathrm{B}}$ (EPDM, H1-60)

$+\quad \mathrm{T}_{\mathrm{A}}$ (EPDM, H1-60)

Measurement Locations

FIG. $6 b$-Samples damaged by burning. 


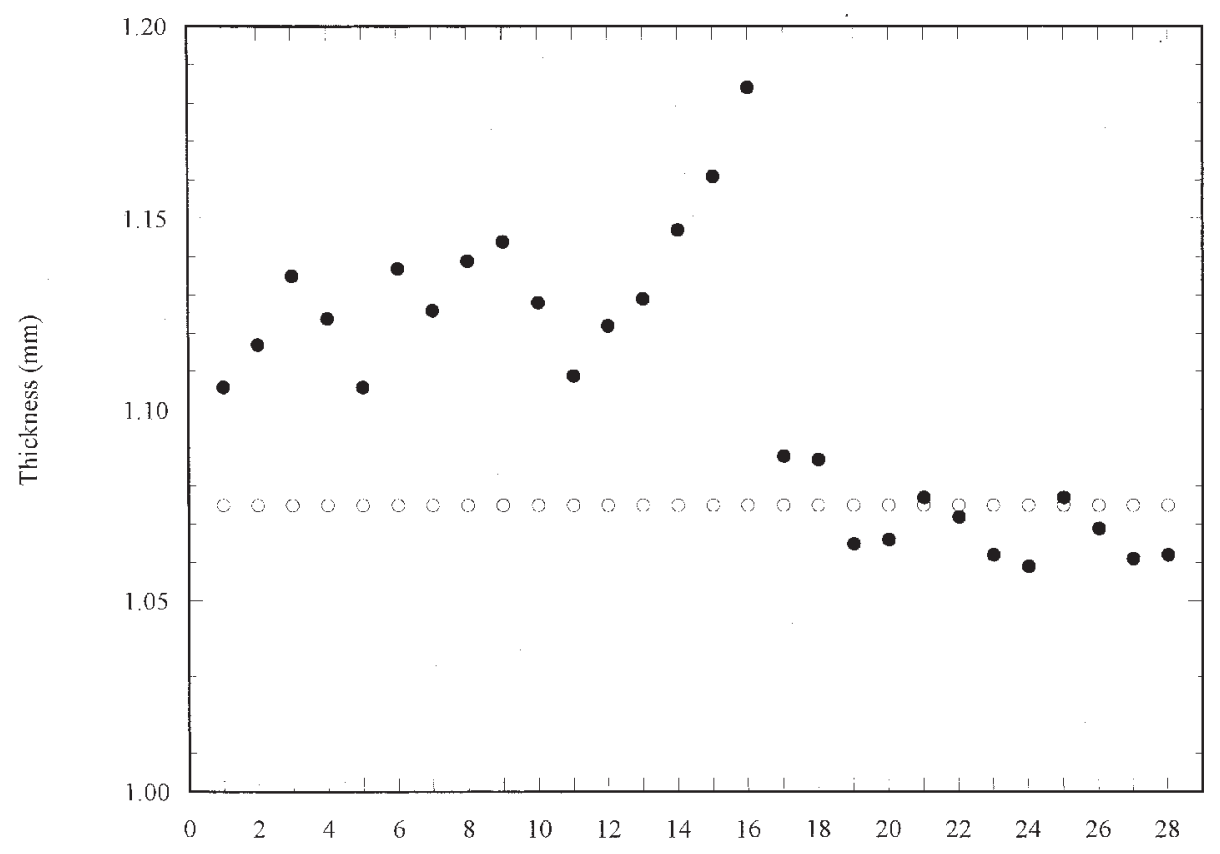

$\mathrm{T}_{\mathrm{B}}(\mathrm{HDPE}, \mathrm{B} 3-40)$
- $\mathrm{T}_{\mathrm{A}}(\mathrm{HDPE}, \mathrm{B} 3-40)$

Measurement Locations

FIG. 6c-Sample damaged by scratching (measurements from the bottom surface).

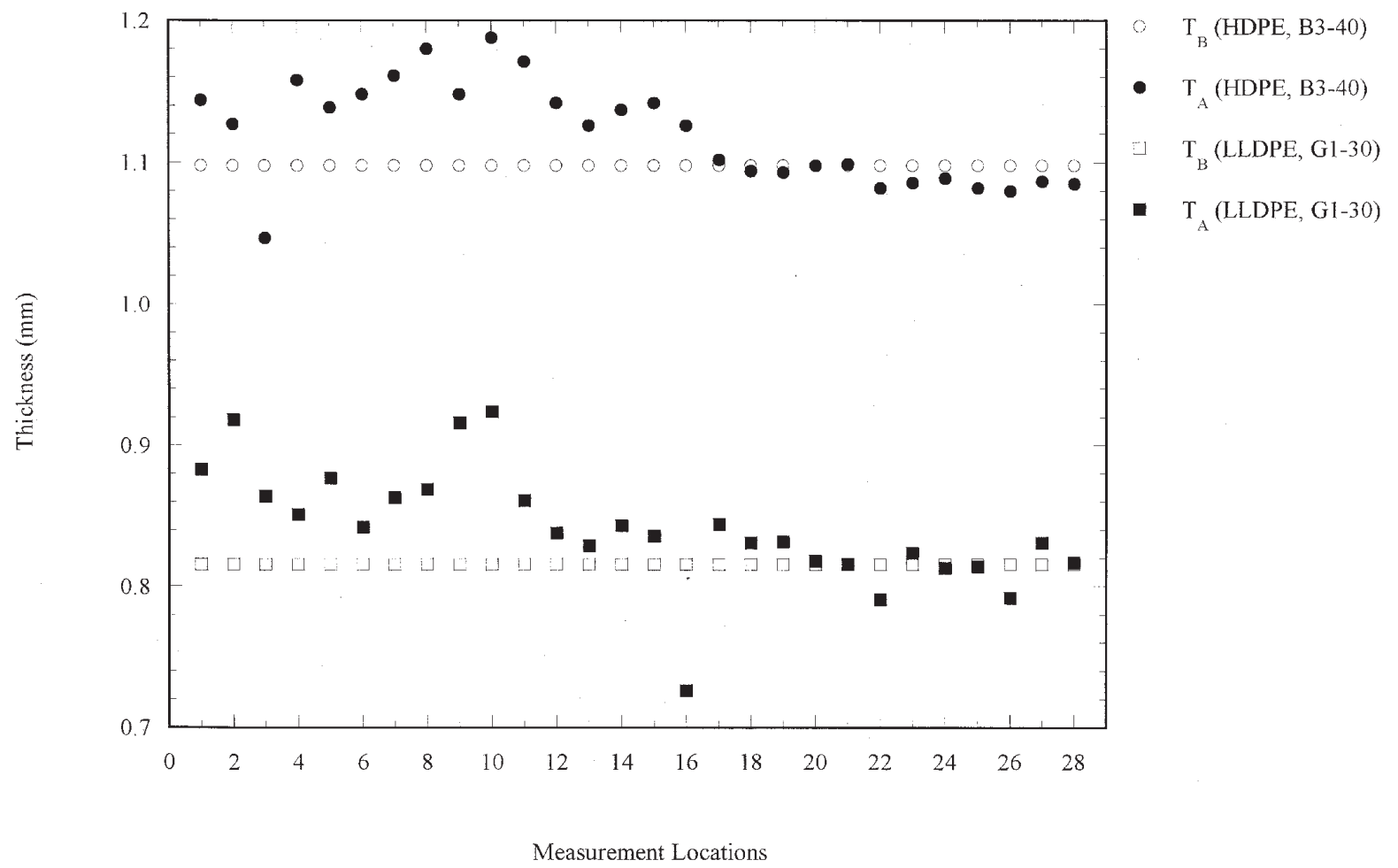

FIG. $6 d-$ Rigid geomembrane samples damaged by opening holes. 


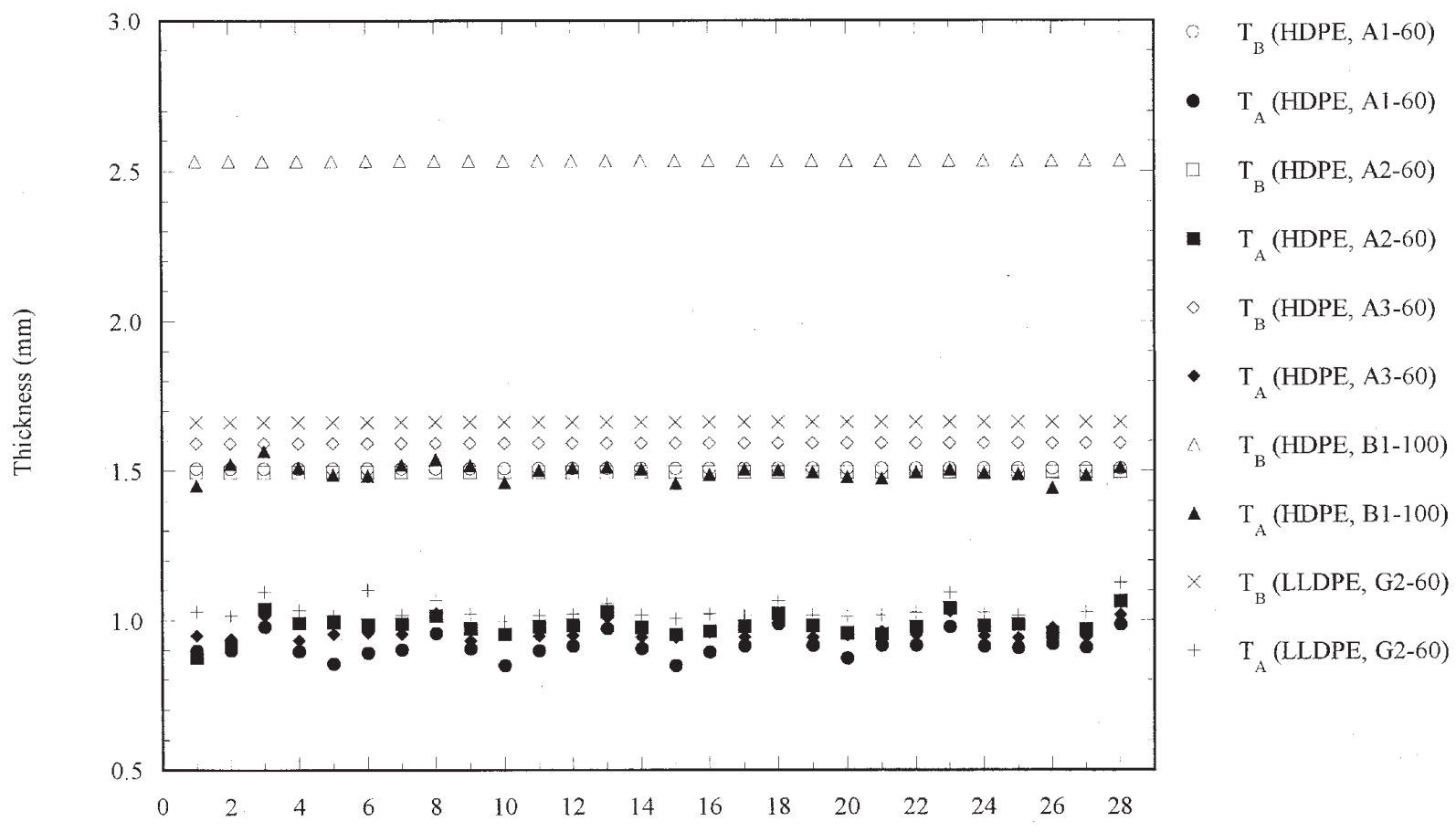

Measurement Locations

FIG. 6e-Samples damaged by layering.

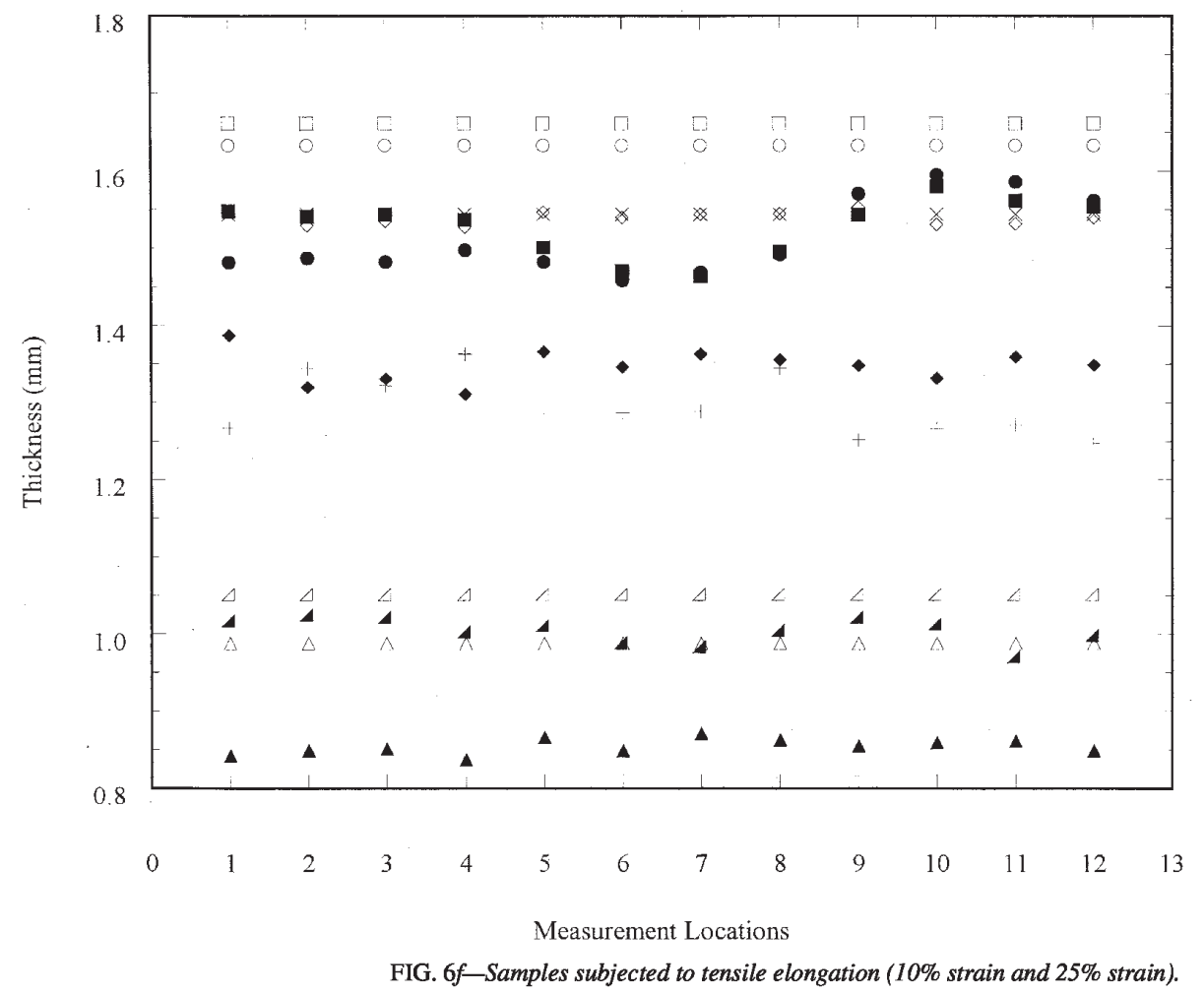

$\mathrm{T}_{\mathrm{B}}$ (HDPE, B2-60, 25\%)

- $\mathrm{T}_{\mathrm{A}}$ (HDPE, B2-60, 25\%)

ᄃ $\mathrm{T}_{\mathrm{B}}$ (LLDPE, G2-60, 25\%)

- $\mathrm{T}_{\mathrm{A}}$ (LLDPE, G2-60, 25\%)

- $\mathrm{T}_{\mathrm{B}}(\mathrm{PVC}, \mathrm{C} 2-60,25 \%)$

- $\mathrm{T}_{\mathrm{A}}(\mathrm{PVC}, \mathrm{C} 2-60,25 \%)$

$\triangle \mathrm{T}_{\mathrm{B}}(\mathrm{PPF} 1-40,25 \%)$

- $\mathrm{T}_{\mathrm{A}}(\mathrm{PPF} \mathrm{F}-40,25 \%)$

$\times \quad \mathrm{T}_{\mathrm{B}}($ EPDM H1-60, 25\%)

$+\mathrm{T}_{\mathrm{A}}(\mathrm{EPDM} \mathrm{H} 1-60,25 \%)$

$\triangle \quad \mathrm{T}_{\mathrm{B}}(\mathrm{PVC}, \mathrm{C} 1-40,10 \%)$

$4 \mathrm{~T}_{\mathrm{A}}(\mathrm{PVC}, \mathrm{C} 1-40,10 \%)$

FIG. $6 f-$ Samples subjected to tensile elongation (10\% strain and 25\% strain). 


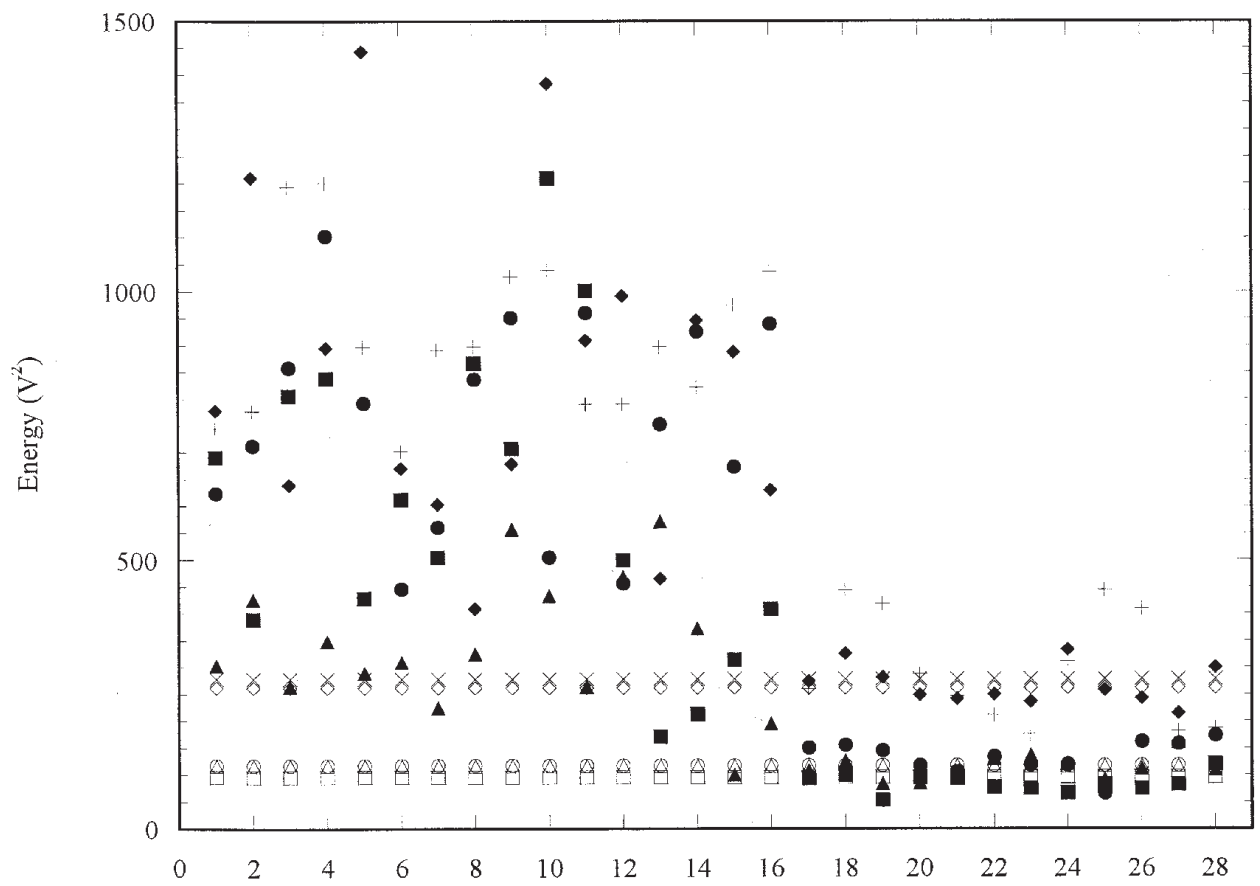

- $\mathrm{E}_{\mathrm{B}}$ (HDPE, B3-40)

- $\mathrm{E}_{\mathrm{A}}$ (HDPE, B3-40)

$\sqcap \quad \mathrm{E}_{\mathrm{B}}(\mathrm{LLDPE}, \mathrm{Gl}-30)$

- $\mathrm{E}_{\mathrm{A}}$ (LLDPE, G1-30)

$\diamond \quad \mathrm{E}_{\mathrm{B}}\left(\mathrm{PVC}, \mathrm{Cl}_{1-40}\right)$

- $\quad \mathrm{E}(\mathrm{PVC}, \mathrm{C} 1-40)$

$\triangle E_{B}(P P, D 1-40)$

- $\mathrm{E}_{\mathrm{A}}(\mathrm{PP}, \mathrm{D} 1-40)$

$\times \quad \mathrm{E}_{\mathrm{B}}(\mathrm{EPDM}, \mathrm{H} 1-60)$

$+\quad \mathrm{E}_{\mathrm{A}}$ (EPDM, H1-60)

Measurement Locations

FIG. 7a-Samples damaged by scratching (measurements from the top surface). 


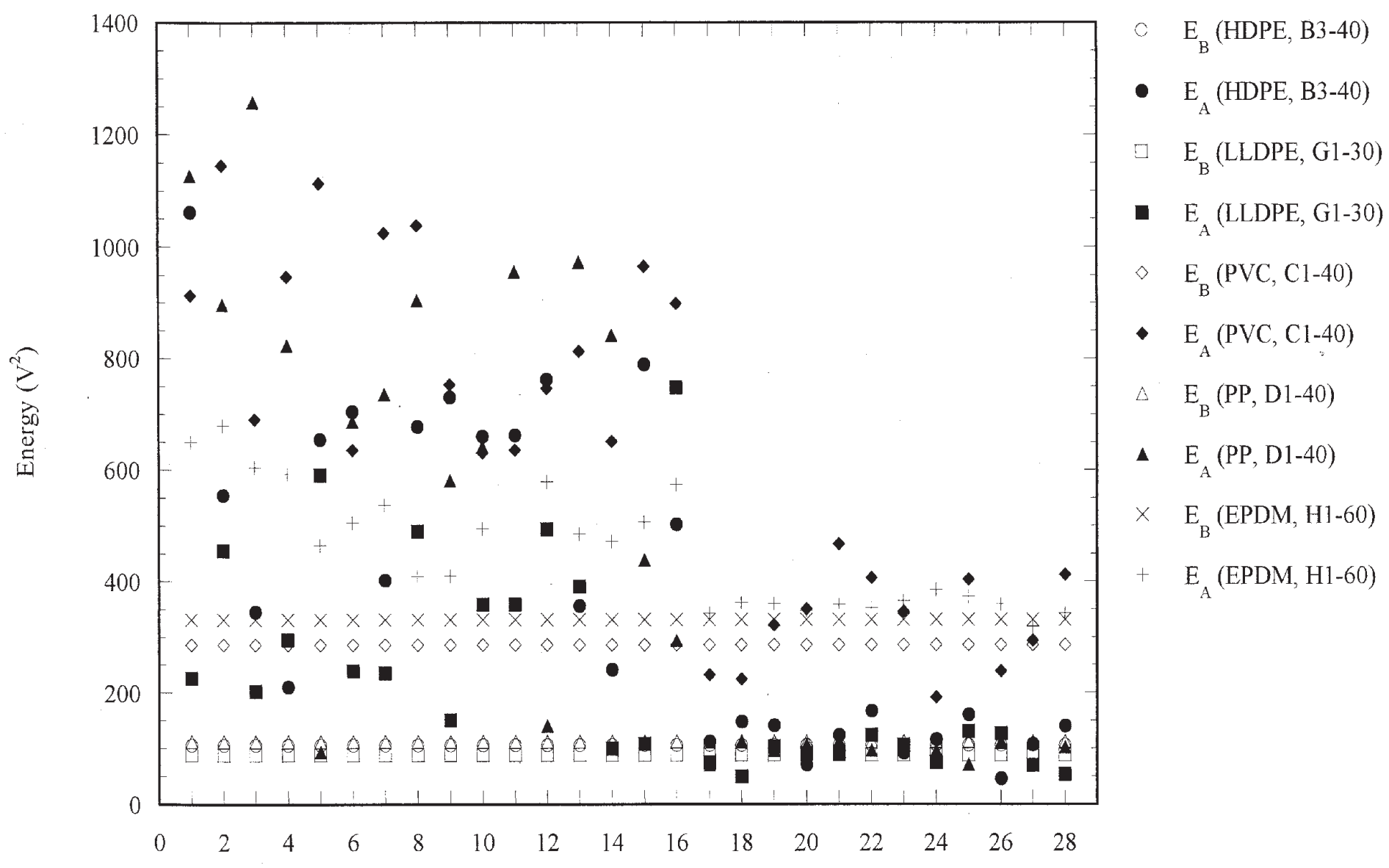

Measurement Locations FIG. $7 b$-Samples damaged by puncturing. 


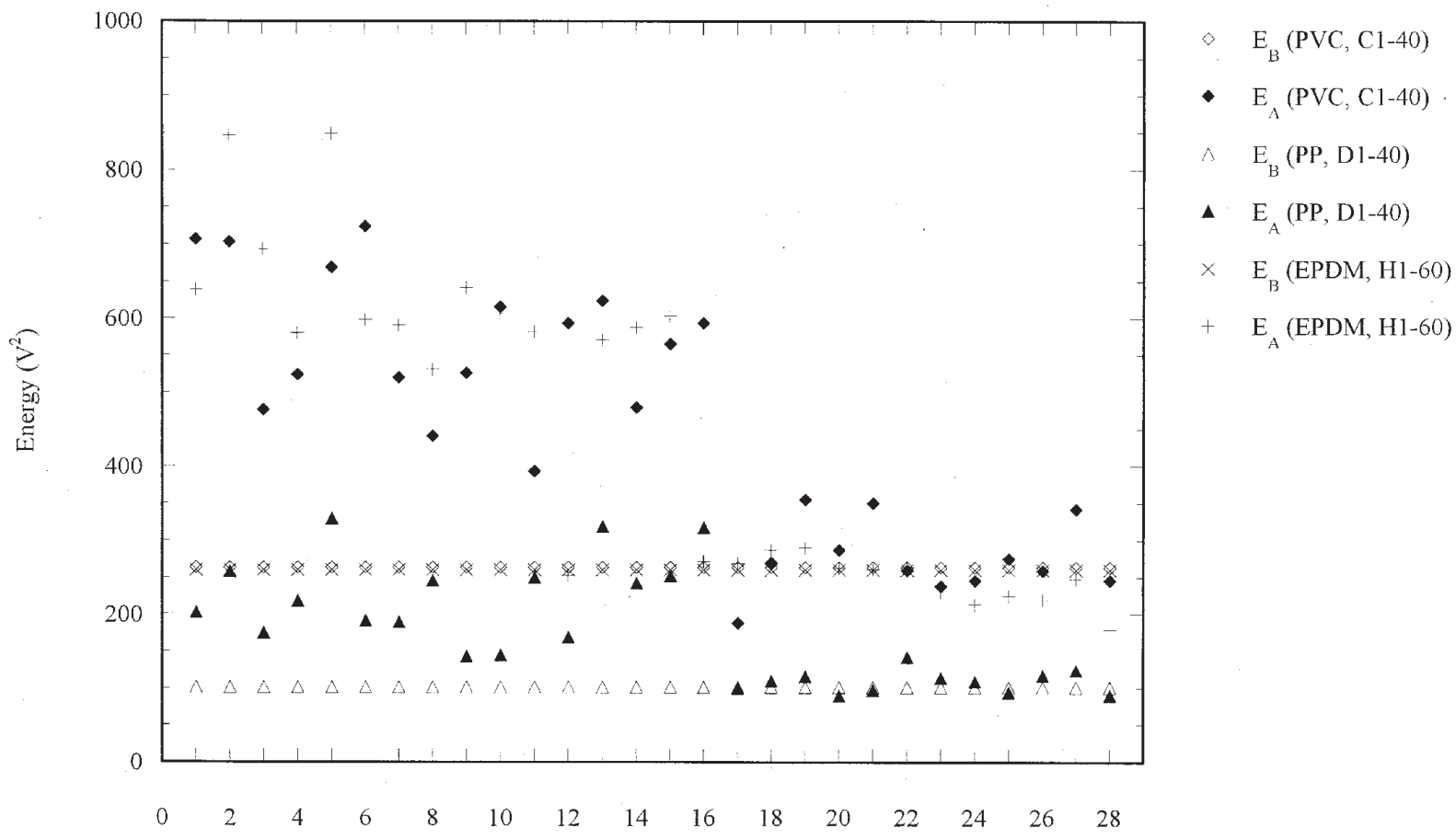

Measurement Locations

FIG. $7 c-$ Flexible geomembrane samples damaged by opening holes.

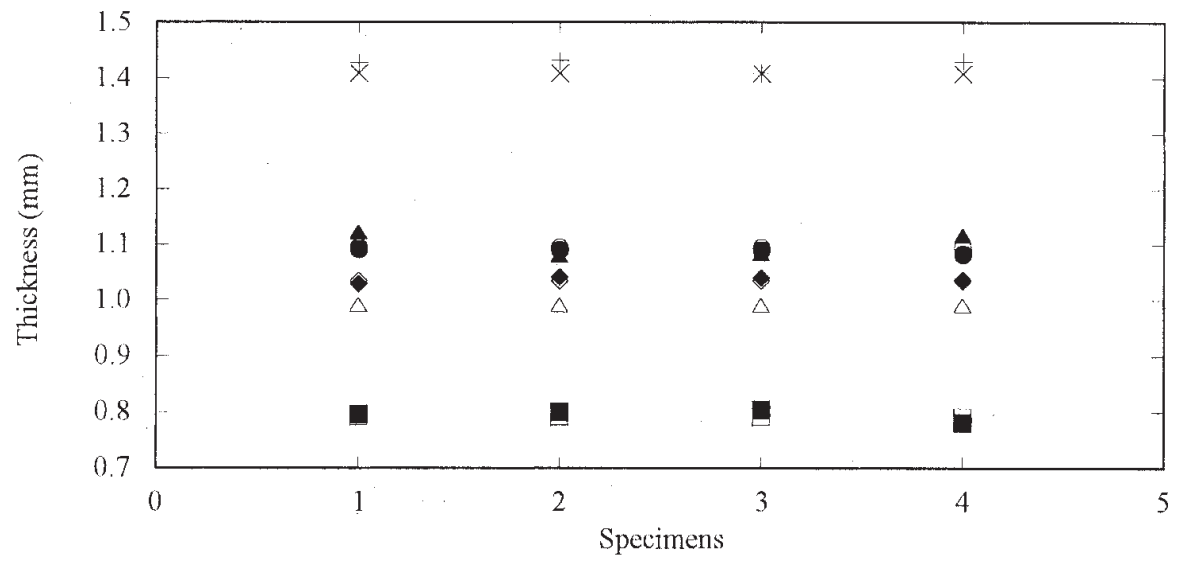

$\mathrm{T}_{\mathrm{B}}(\mathrm{HDPE}, \mathrm{B} 3-40)$

- $\mathrm{T}_{\mathrm{A}}(\mathrm{HDPE}, \mathrm{B} 3-40)$

$\square \quad \mathrm{T}_{\mathrm{B}}$ (LLDPE, G1-30)

- $\mathrm{T}_{\mathrm{A}}$ (LLDPE, G1-30)

$\diamond T_{B}^{A}$ (PVC, $\left.\mathrm{Cl}-40\right)$

- $\mathrm{T}_{\mathrm{A}}(\mathrm{PVC}, \mathrm{C1-40)}$

$\triangle \mathrm{T}_{\mathrm{B}}(\mathrm{PP}, \mathrm{D} 1-40)$

- $\mathrm{T}_{\mathrm{A}}(\mathrm{PP}, \mathrm{D} 1-40)$

$\times \mathrm{T}_{\mathrm{B}}(\mathrm{EPDM}, \mathrm{H1}-60)$

$+T_{A}(E P D M, H 1-60)$

(a) UV Light

FIG. 8a-Samples exposed to UV light. 


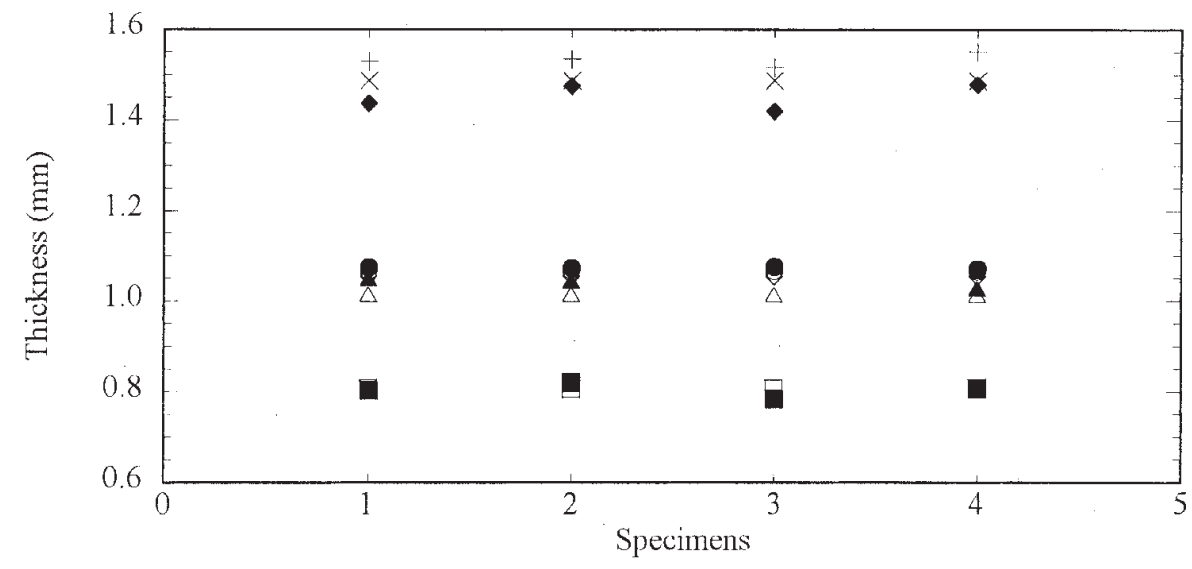

O $\mathrm{T}_{\mathrm{B}}$ (HDPE, B3-40)

- $\mathrm{l}$ (HDPE, B3-40)

-1 $\mathrm{T}_{\mathrm{B}}^{\mathrm{A}}$ (LLDPE, G1-30)

- T (LLDPE, G1-30)

$\diamond \Gamma_{B}^{A}(P V C, C 1-40)$

$-T^{B}(\mathrm{PVC}, \mathrm{C} 1-40)$

$\triangle \mathrm{T}_{\mathrm{B}}(\mathrm{PP}, \mathrm{D} 1-40)$

- $\mathrm{T}(\mathrm{PP}, \mathrm{D} 1-40)$

$\times \mathrm{T}_{\mathrm{B}}$ (EPDM, H1-60)

$+\mathrm{T}_{\mathrm{A}}$ (EPDM, H1-60)

(b) Acetone

FIG. $8 b$-Samples exposed to acetone.

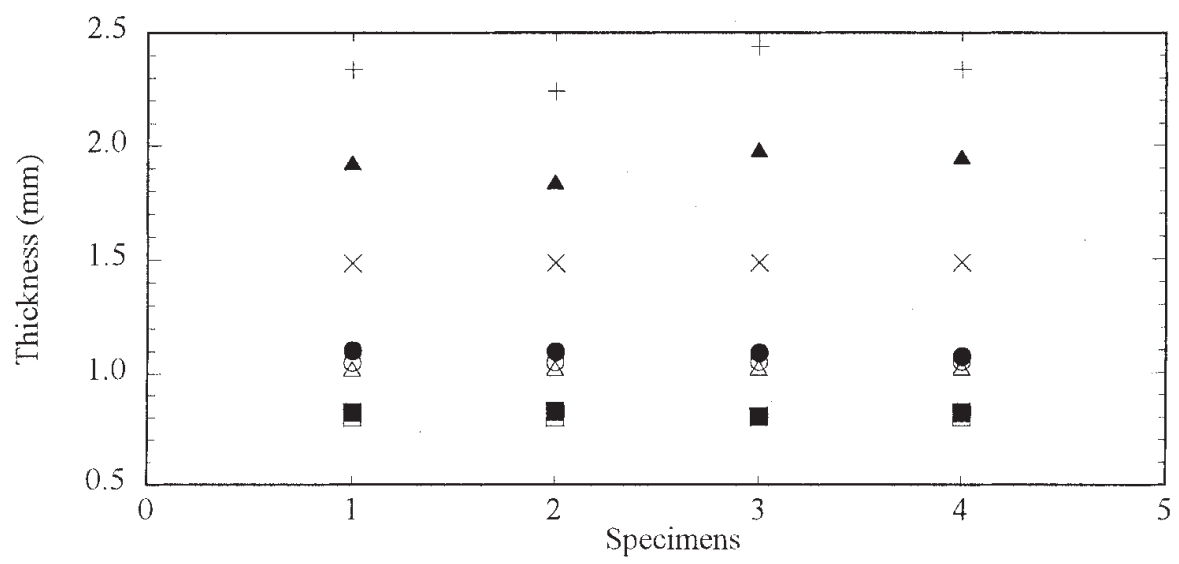

- $\mathrm{T}_{\mathrm{B}}$ (HDPE, B3 -40)

- $\mathrm{T}_{\mathrm{A}}$ (HDPE, B3-40)

$\square \quad \mathrm{T}_{\mathrm{B}}$ (LLDPE, G1-30)

- $\mathrm{T}_{\mathrm{A}}$ (LLDPE, G1-30)

$\triangle \mathrm{T}_{\mathrm{B}}(\mathrm{PP}, \mathrm{D} 1-40)$

- $\mathrm{T}_{\mathrm{A}}(\mathrm{PP}, \mathrm{D} 1-40)$

$\times \mathrm{T}_{\mathrm{B}}$ (EPDM, H1-60)

$+\mathrm{T}_{\mathrm{A}}(\mathrm{EPDM}, \mathrm{H1}-60)$

(c) Toluene

FIG. 8c-Samples exposed to toluene.

TABLE 5-Results of chemical exposure tests.

\begin{tabular}{|c|c|c|c|c|c|c|c|c|c|c|c|c|}
\hline \multirow[b]{3}{*}{ Sample } & \multicolumn{12}{|c|}{ Variation in Properties, \% } \\
\hline & \multicolumn{6}{|c|}{ Acetone Immersion } & \multicolumn{6}{|c|}{ Toluene Immersion } \\
\hline & $V^{1}$ & $W^{2}$ & $D^{3}$ & $S G^{4}$ & $D C^{5}$ & $M T^{6}$ & $V$ & $W$ & $D$ & $S G$ & $D C$ & $M T$ \\
\hline HDPE & 1 & 1 & 3 & 13 & 23 & 1 & 9 & 8 & 4 & 23 & 15 & 2 \\
\hline PVC & 30 & 106 & 39 & 22 & $\ldots$ & $\ldots$ & $\ldots$ & $\ldots$ & $\ldots$ & $\ldots$ & $\ldots$ & $\ldots$ \\
\hline PP & 5 & 3 & 4 & 23 & 50 & 10 & 28 & 103 & 20 & 11 & 21 & 14 \\
\hline LLDPE & 1 & 1 & 2 & 11 & 18 & 2 & 8 & 6 & 4 & 30 & 16 & 3 \\
\hline EPDM & 4 & 1 & 4 & 29 & $\ldots$ & $\ldots$ & 17 & 79 & 32 & 28 & $\ldots$ & $\ldots$ \\
\hline
\end{tabular}

${ }^{1}$ P-Wave Velocity, ${ }^{2}$ Weight, ${ }^{3}$ Diameter, ${ }^{4}$ Specific Gravity, ${ }^{5}$ Degree of Crystallinity, ${ }^{6}$ Melting Temperature, (...) Data not Available. 